\title{
Non-isolated high step-up DC-DC converter adopting auxiliary capacitor and coupled inductor
}

\author{
Gang WU ${ }^{1}$, Xinbo RUAN ${ }^{1}$, Zhihong $\mathrm{YE}^{2}$
}

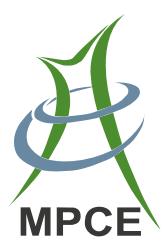

\begin{abstract}
For grid-connected power system based on photovoltaic (PV) source and fuel cells, high step-up and high-efficiency DC-DC converters are needed, due to the bus voltage of the grid-connected inverter is much higher than the output voltage of PV and fuel cells. In this paper, a novel high step-up converter is proposed. An auxiliary capacitor is introduced into the boost converter, which serves as a voltage source. It is in series with the input voltage source with the same voltage polarities. Thus, the input voltage is increased equivalently and the voltage gain is increased accordingly. To reduce the voltage stresses of the switch and the diode, multiple output capacitors are introduced. The voltage of each output capacitor is degraded leading to the reduced voltage stress. To replenish energy for the multiple output capacitors, a coupled inductor is adopted. Based on this, high step-up converter adopting auxiliary capacitor and coupled inductor is derived. The operating principles and voltage gain of the proposed converters are analyzed in this paper. In the
\end{abstract}

CrossCheck date: 2 August 2017

Received: 15 November 2016/Accepted: 2 August 2017/Published online: 1 December 2017

(C) The Author(s) 2017. This article is an open access publication

$\triangle$ Gang WU

wugang@nuaa.edu.cn

Xinbo RUAN

ruanxb@nuaa.edu.cn

Zhihong YE

sam.ye@liteon.com

1 College of Automation Engineering, Nanjing University of Aeronautics and Astronautics, Nanjing 211106, China

2 Power SBG ATD-NJ R\&D Center, Lite-On Technology Corp, Nanjing 210019, China end, experiment results are given to verify the theoretical analysis.

Keywords High voltage gain, High efficiency, Nonisolated, Photovoltaic (PV), Fuel cell

\section{Introduction}

Since it takes centuries for the traditional fossil energy to be replenished, it will be exhausted with the growing demand for energy of human society. Thus the energy crisis is increasingly serious. Meanwhile, the excessive usage of the traditional fossil energy has polluted the environment and resulted in greenhouse effect on a global scale [1]. Therefore, it is becoming more and more important to optimize the energy consumption structure and to utilize clean and renewable energy. Solar energy and hydrogen energy are two promising renewable energy, and have extensive application prospect. As the utilization methods of the two new energy, photovoltaic (PV) and fuel cells power generations have been applied on a large scale [2-7], such as photovoltaic power station and electric vehicle.

In recent years, the grid-connected power generation based on PV source for residential application has become globally popular. Usually, an interface unit is necessary, as the output voltage of PV source is relatively too low for the line voltage. If the line voltage is $220 \mathrm{~V}$, the input voltage needed by the grid-connected inverter would approach $380 \mathrm{~V}$. But the output voltage of PV source generally varies from 25 to $45 \mathrm{~V}$. To boost the output voltage of PV source, one possible solution to is to make series-connected PV arrays. But the total output power of PV arrays will be degraded due to module mismatch or partial shading [8]. 
Another promising solution is to utilize a high step-up DCDC converter to match the low output voltage of PV source and high input voltage of the inverter. Then every PV source can realize the function of maximum power point tracking. For the isolated DC-DC converters, the voltage gain can be increased by adjusting the turns ratio of the transformer. But the energy stored in the leakage inductor is difficult to be transferred to the output. Thus, for the application without galvanic isolation requirement, nonisolated high step-up DC-DC converters is preferred.

The boost converter is wildly used for voltage step-up. However, its duty cycle would be too large when the input voltage is much smaller than the output. And for the actual power switch and diode, a certain delay between turn-on and turn-off state will probably result that the power switch is turned on before being cut off completely and the diode is cut off before conducting. Thus, the reliability is degraded. When the duty cycle approaches unity, a large pulse current will conduct through the diode in a short time, which leads to large the current stress of the diode and severe reverse recovery problem. This will greatly affect the efficiency and brings about a serious electromagnetic interference problem [9-12]. By cascading another boost converter, a high voltage gain can be easily obtained. But the additional switch makes the control scheme more complex. And it may cause instability issue for cascaded systems.

The impedance source networks are widely used in the inverters [13-16] to increase the voltage boost inversion ability. Likewise, the impedance source networks can also be used in high step-up DC-DC converters to achieve high voltage gain [17-20]. The converters can operate with a much smaller duty cycle, which improves the reliability. By combining quasi-Z-source network and transformer, the voltage stress of the switch is reduced. But most of the converters adopt multiple power switches, and have a relatively complex control scheme. In [21], a single power switch was adopted to simplify the control design. However, the voltage stress of the switch is as high as the output voltage, which brings large switching loss.

Another method of increasing the voltage gain is to introduce a coupled inductor [22-28]. However, the current through the coupled inductor is discontinuous. It goes against the lifetime of PV and fuel cell when the coupled inductor is placed on the input side. Especially for the low input voltage application, the input current is very large. Thus, the continuous input current is preferred.

To overcome the respective disadvantages of quasi-Zsource network and coupled inductor, some isolated high step-up DC-DC converters combining quasi-Z-source network and coupled inductor are proposed in [29, 30]. However, due to the isolation, the energy stored in the leakage inductor of the primary winding is difficult to be transferred to the output. In this paper, a non-isolated high step-up DC-DC converter with single switch based on quasi-Z-source network and coupled inductor is proposed. The input current is continuous and the voltage stress of the switch is low. Besides, the energy stored in the leakage inductor can be absorbed by the output capacitor, which is beneficial for the efficiency. And single switch is used to simplify the control scheme. The operating principle and parameter calculation are given in this paper, and an experiment is conducted to verify the theoretical analysis. The experiment results indicate that the proposed converters can achieve a higher efficiency.

\section{Derivation of high step-up DC-DC converters adopting auxiliary capacitor and coupled inductor}

\subsection{High step-up converter adopting auxiliary capacitor}

Figure 1 gives the basic boost converter, where $V_{\mathrm{g}}$ is the input voltage, $L_{1}$ is the boost inductor, $\mathrm{Q}$ is the switch. To increase the voltage gain of boost converter, an auxiliary voltage source $V_{\mathrm{a}}$ can be introduced to the input terminal and the voltage polarity is the same as $V_{\mathrm{g}}$, as shown in Fig. 2. When $\mathrm{Q}$ is turned on, $V_{\mathrm{g}}$ is in series with $V_{\mathrm{a}}$ to charge $L_{1}$. When Q is turned off, $V_{\mathrm{g}}$ is in series with $V_{\mathrm{a}}$ and $L_{1}$ to supply the load. And the output voltage is the sum of $V_{\mathrm{g}}, V_{\mathrm{a}}$ and the voltage of $L_{1}$. Obviously, the auxiliary voltage source increases the input voltage equivalently, and a high voltage gain is obtained.

The auxiliary voltage source $V_{\mathrm{a}}$ in Fig. 2 can be implemented with a capacitor $C_{\mathrm{a} 1}$, which is defined as the auxiliary capacitor. To replenish energy for the auxiliary capacitor $C_{\mathrm{a} 1}$, the inductor $L_{2}$, and the diode $\mathrm{D}_{1}$ is introduced as shown in Fig. 3a. Obviously, the larger the voltage of the auxiliary capacitor is, the higher the derived voltage gain will be. To obtain a higher voltage for $C_{\mathrm{a} 1}$, an additional auxiliary voltage source $V_{\mathrm{a}}$ can be added in the charging path of $L_{2}$, as shown in Fig. 3b. When $Q_{a}$ is turned on, $V_{\mathrm{a}}$ is in series with the input voltage source to charge $L_{2}$. When $\mathrm{Q}_{\mathrm{a}}$ is turned off, $L_{2}$ replenishes energy for $C_{\mathrm{a} 1}$. If $V_{\mathrm{a}}$ is equal to the electric potential difference between nodes $a$ and $b$, the electric potentials of the drain electrodes are identical and can be connected directly. In

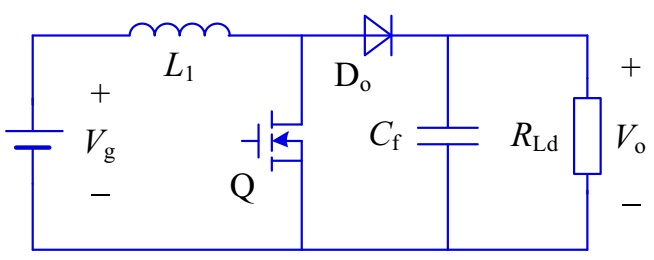

Fig. 1 Basic boost converter 


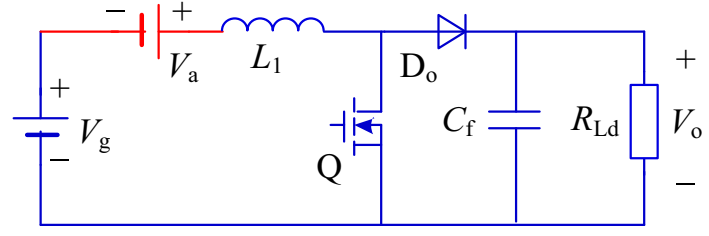

Fig. 2 Boost converter adopting auxiliary voltage source

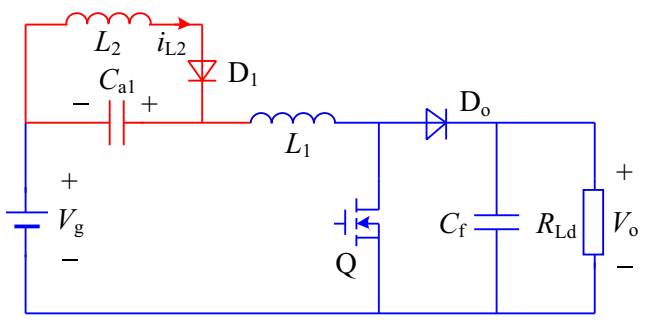

(a) Step 1 (incomplete topology)

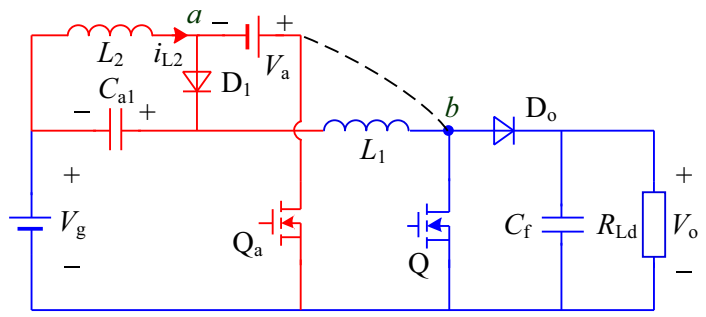

(b) Step 2

Fig. 3 Derivation process

doing so, $\mathrm{Q}_{\mathrm{a}}$ can be removed to simplify the structure. Likewise, the auxiliary voltage source $V_{\text {a }}$ can be implemented by a capacitor $C_{\mathrm{a} 2}$, as shown in Fig. 4. As seen, $L_{1}$ can be used to replenish energy for $C_{\mathrm{a} 2}$. This topology has been proposed and analyzed in [19], which is called Z-source DC-DC converter.

As the voltages of $C_{\mathrm{a} 1}$ and $V_{\mathrm{g}}$ in Fig. 4 are constant, the voltage between nodes $c$ and $d$ is also constant and equals the voltage sum of $C_{\mathrm{a} 1}$ and $V_{\mathrm{g}}$. Thus, a capacitor can be added between nodes $\mathrm{C}$ and $\mathrm{D}$ to serve as a new input source of the boost inductor $L_{1}$. As the new capacitor charges $L_{1}$ instead of the original one, the original auxiliary capacitor can be removed as shown in Fig. 5. This structure consisting of the capacitor and inductor is called quasi-Z-

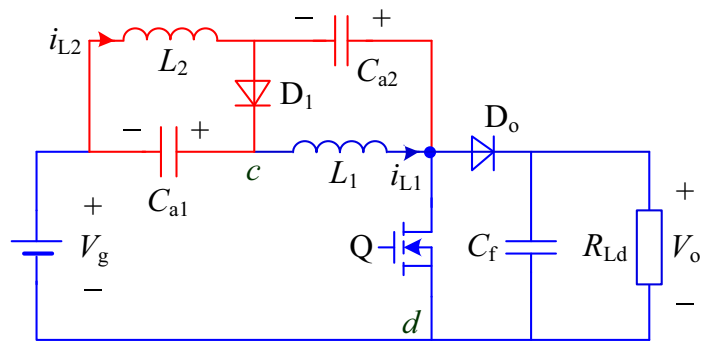

Fig. 4 Transition structure (Z-source DC-DC converter)

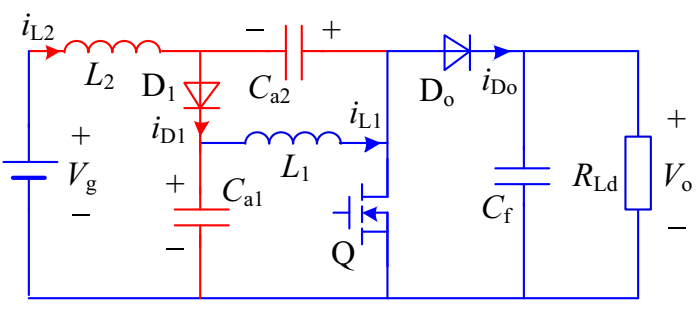

Fig. 5 High step-up converter adopting auxiliary capacitor

source network [13]. Its operating modes when the network is applied for DC-DC converter with single switch has not been analyzed in detail in [13].

Compared with the converter shown in Fig. 4, the voltage stress of $C_{\mathrm{a} 1}$ in Fig. 5 is larger. But the input current of the converter in Fig. 5 is continuous, which is beneficial for improving the lifetime of PV and fuel cell.

As shown in Fig. 5, the voltage stresses of the switch and the diode are both as high as the output voltage which leads to a large conduction resistor of the switch and severe reverse recovery problem of the diode. Thus, the conduction loss and the switching loss are both large.

\subsection{High step-up converter adopting auxiliary capacitor and coupled inductor}

To reduce the voltage stress of the switch and the diode, referring to [31], multiple output capacitors can be used to supply the load, as shown in Fig. 6a. In doing so, the voltage of $C_{\mathrm{o} 1}$ is reduced, and the voltage stress of $\mathrm{Q}, \mathrm{D}_{1}$ and $\mathrm{D}_{\mathrm{o} 1}$ are reduced as well. To replenish energy for $C_{\mathrm{o} 2}$, the inductor $L_{1}$ in Fig. 5 is replaced by the coupled inductor $L_{\mathrm{cp}}$, and the secondary winding of the coupled inductor is used to charge $C_{\mathrm{o} 2}$. In [31], the inductor of the boost converter is replaced by the coupled inductor, which leads to a discontinuous input current. On the contrary, the input current of the converter in Fig. $6 \mathrm{~b}$ remains continuous, which is beneficial for the lifetime of PV and fuel cell.

As shown in Fig. 6b, the voltage doubling rectifier circuit is adopted to further increase the voltage of $C_{\mathrm{o} 2}$ in order to reduce the voltage stresses of $Q, D_{1}$ and $D_{o 1}$. As a result, a switch with a lower conduction resistor can be selected, and the conduction loss and switching loss can be reduced.

\section{Analysis of high step-up DC-DC converters adopting auxiliary capacitor and coupled inductor}

\subsection{Operating principle of CCM}

Considering the parasitic parameters of the coupled inductor, the equivalent circuit is given in Fig. 7. When the 


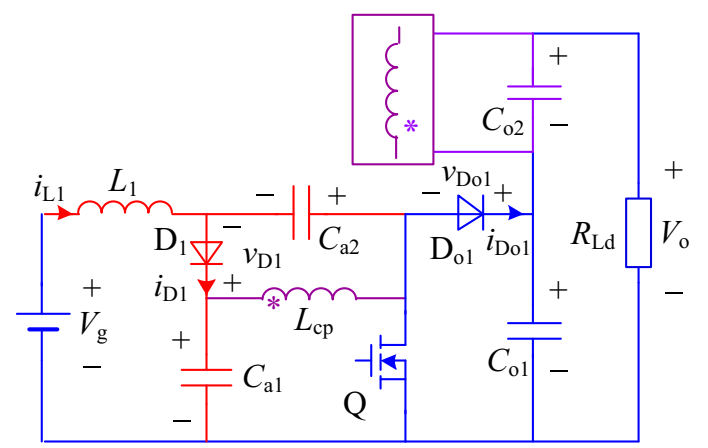

(a) Derivation progress

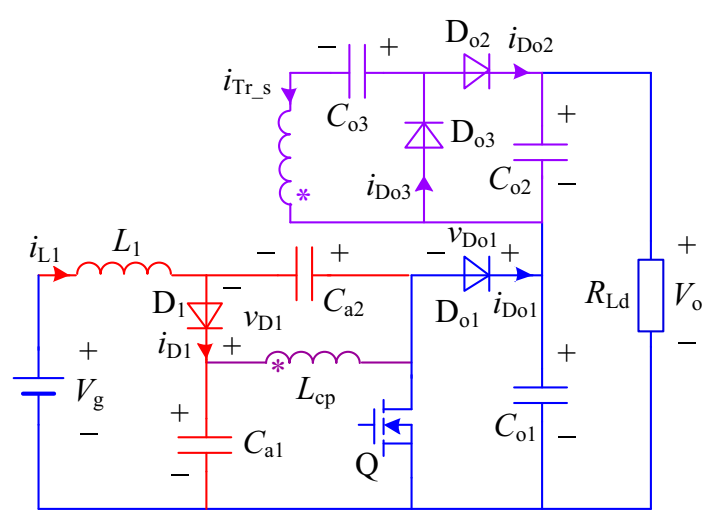

(b) Complete topology

Fig. 6 High step-up converter adopting auxiliary capacitor and coupled inductor

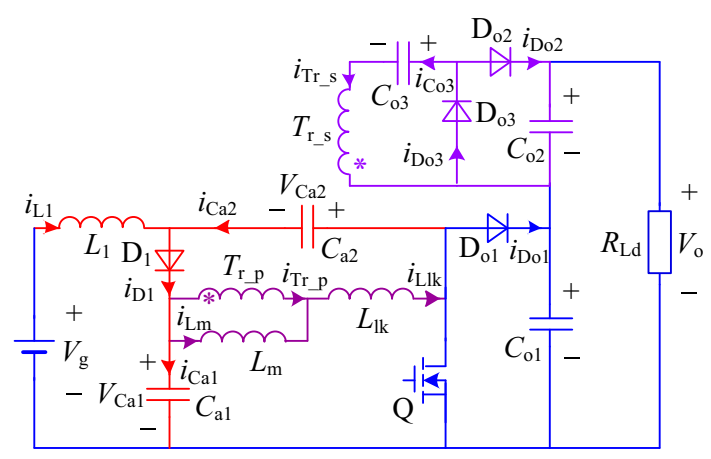

Fig. 7 Equivalent circuit

currents of $L_{1}$ and the magnetizing inductor $L_{\mathrm{m}}$ are both continuous, there exist four operating modes and the key waveforms are shown in Fig. 8, where $i_{\mathrm{L} 1}$ is the current of $L_{1}, i_{\text {Tr_s }}$ is the current of the secondary winding of the coupled inductor, $i_{\mathrm{Lm}}$ and $i_{\mathrm{Llk}}$ are the currents of the magnetizing inductor and the leakage inductor of the coupled inductor respectively, $i_{\mathrm{D} 1}$ and $i_{\mathrm{Do} 1}$ are the currents of $\mathrm{D}_{1}$ and $\mathrm{D}_{\mathrm{o} 1}$. The operating modes are shown in Fig. 9.

Mode $1\left[t_{1} \sim t_{2}\right]$ : When $\mathrm{Q}$ is turned on, $V_{\mathrm{g}}$ is in series with $C_{\mathrm{a} 2}$ to charge $L_{1}$, and $C_{\mathrm{a} 1}$ charges the magnetizing inductor $L_{\mathrm{m}}$. In this mode, the secondary winding of the coupled inductor charges $C_{\mathrm{o} 3}$ through $\mathrm{D}_{\mathrm{o} 3}$.

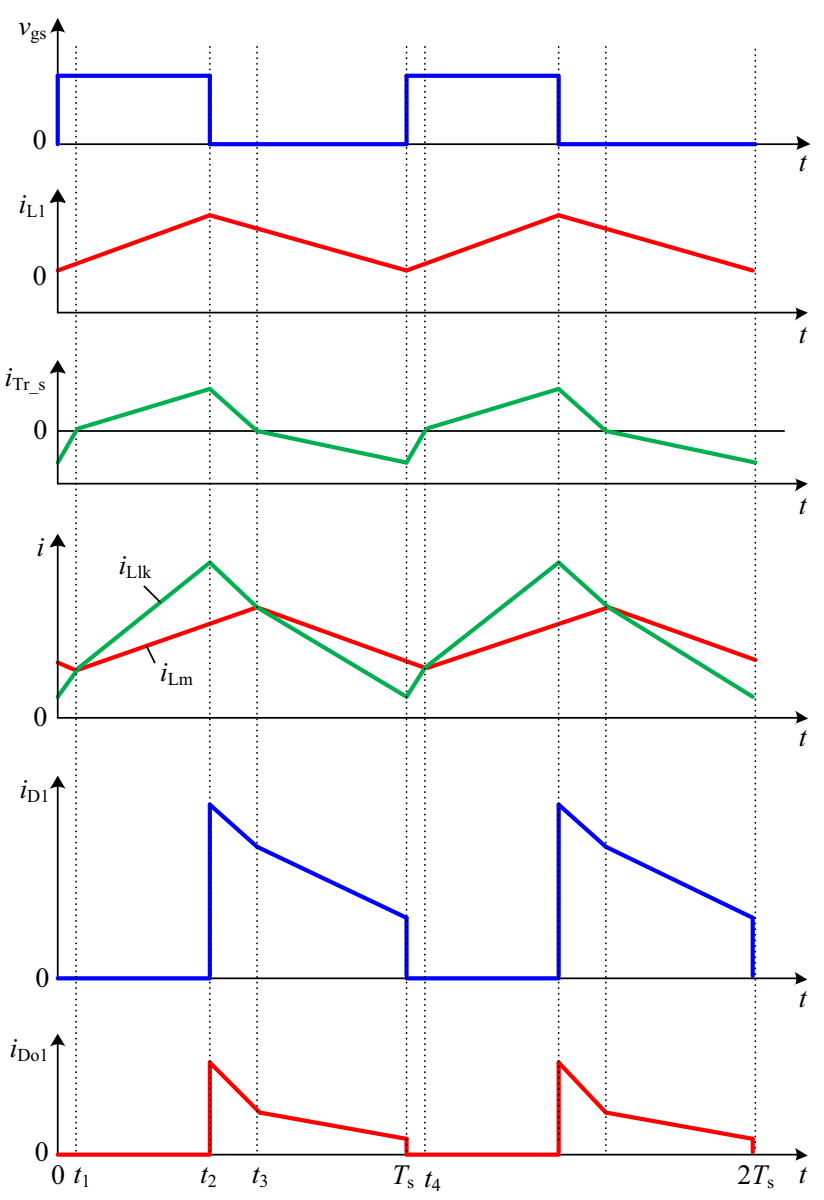

Fig. 8 Key waveforms in CCM

Mode $2\left[t_{2} \sim t_{3}\right]$ : When $\mathrm{Q}$ is turned off, $L_{1}$ and $L_{\mathrm{m}}$ charge $C_{\mathrm{a} 1}$ and $C_{\mathrm{a} 2}$ through $\mathrm{D}_{1}$ respectively, and the input voltage source is in series with $L_{1}$ and $L_{\mathrm{m}}$ to charge $C_{\mathrm{o} 1}$. In this mode, $i_{\mathrm{Lm}}$ is smaller than $i_{\mathrm{Llk}}$, where $i_{\mathrm{Lm}}$ and $i_{\mathrm{Llk}}$ are the currents of the leakage inductor and the magnetizing inductor, respectively. Thus, the current direction of the secondary winding remains and the secondary winding still charges $C_{\mathrm{0} 3}$ through $\mathrm{D}_{\mathrm{o} 3}$.

Mode $3\left[t_{3} \sim T_{\mathrm{s}}\right.$ ]: In this mode, $i_{\mathrm{Lm}}$ is larger than $i_{\mathrm{Llk}}$, leading to the current direction of the secondary winding changed. And the secondary winding charges $C_{\mathrm{o} 2}$ in series with $C_{\mathrm{o} 3}$ through $\mathrm{D}_{\mathrm{o} 2}$.

Mode $4\left[T_{\mathrm{s}} \sim t_{4}\right]$ : In this mode, since $i_{\mathrm{Lm}}$ is larger than $i_{\mathrm{L} 1 \mathrm{k}}$, the secondary winding still charges $C_{\mathrm{o} 2}$ in series with $C_{\mathrm{o} 3}$ through $\mathrm{D}_{\mathrm{o} 2}$.

\subsection{Operating principle of DCM}

When the current of $L_{1}$ is discontinuous, the key waveforms and operating modes in DCM are shown as Figs. 10 and 11, respectively. There are five operating modes for DCM, in which Mode 1, Mode 2, and Mode 3 


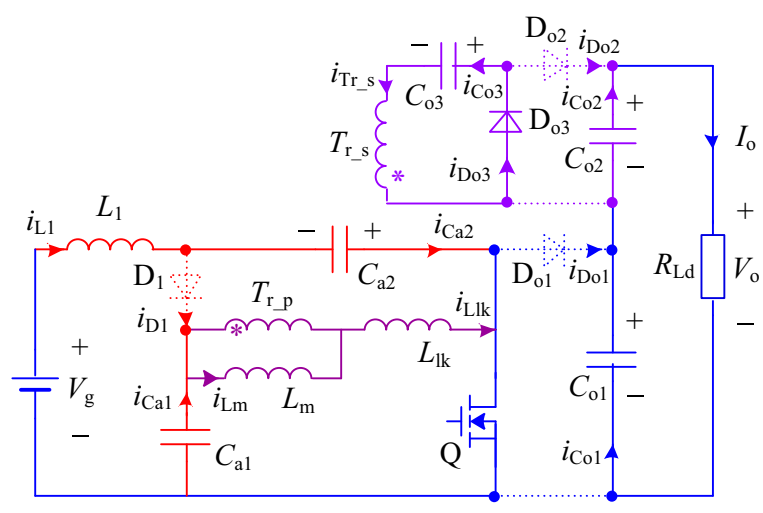

(a) Mode $1\left[t_{1} \sim t_{2}\right]$

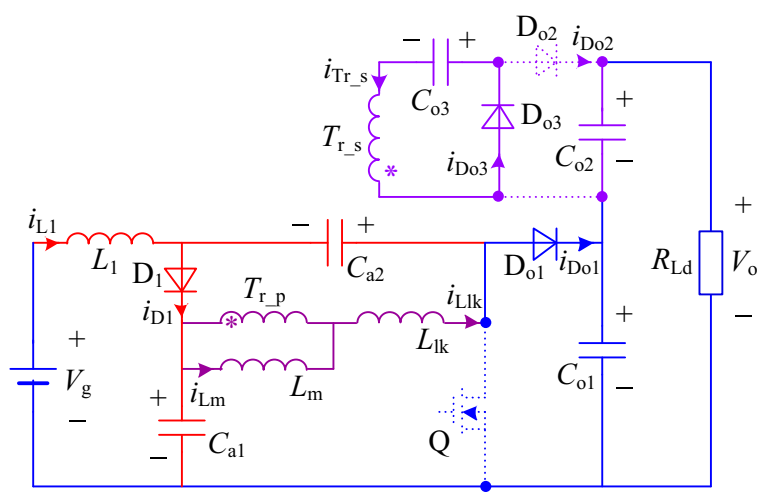

(b) Mode $2\left[t_{2} \sim t_{3}\right]$

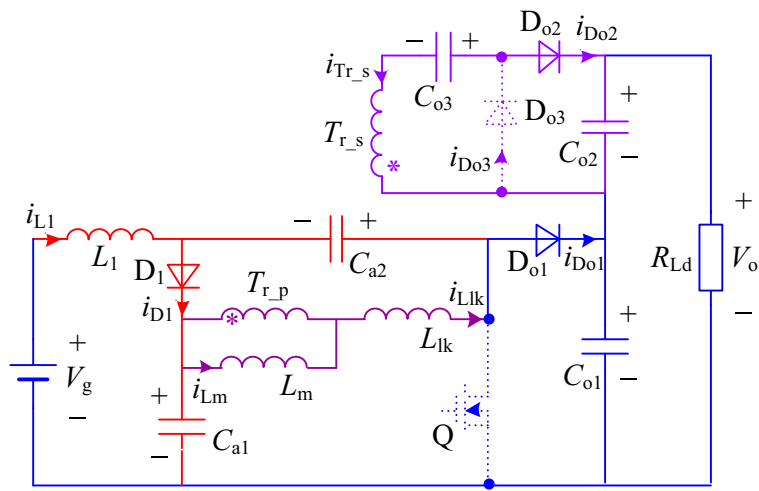

(c) Mode $3\left[t_{3} \sim T_{\mathrm{s}}\right]$

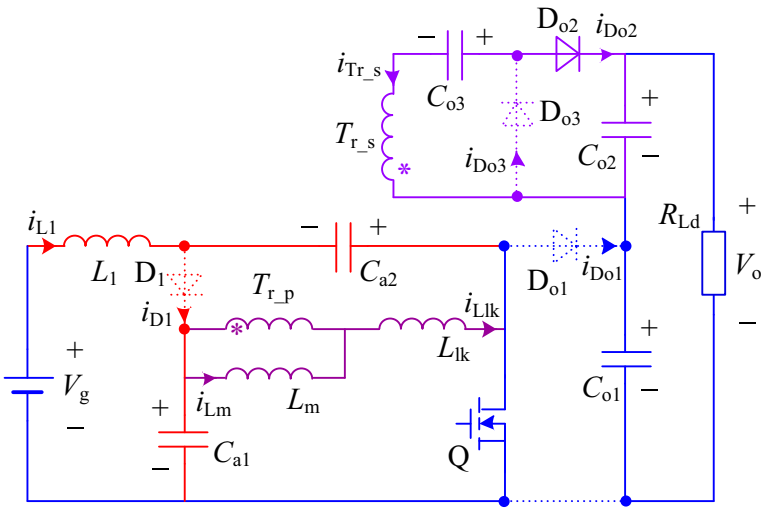

(d) Mode $4\left[T_{\mathrm{s}} \sim t_{4}\right]$

Fig. 9 Operating modes in CCM

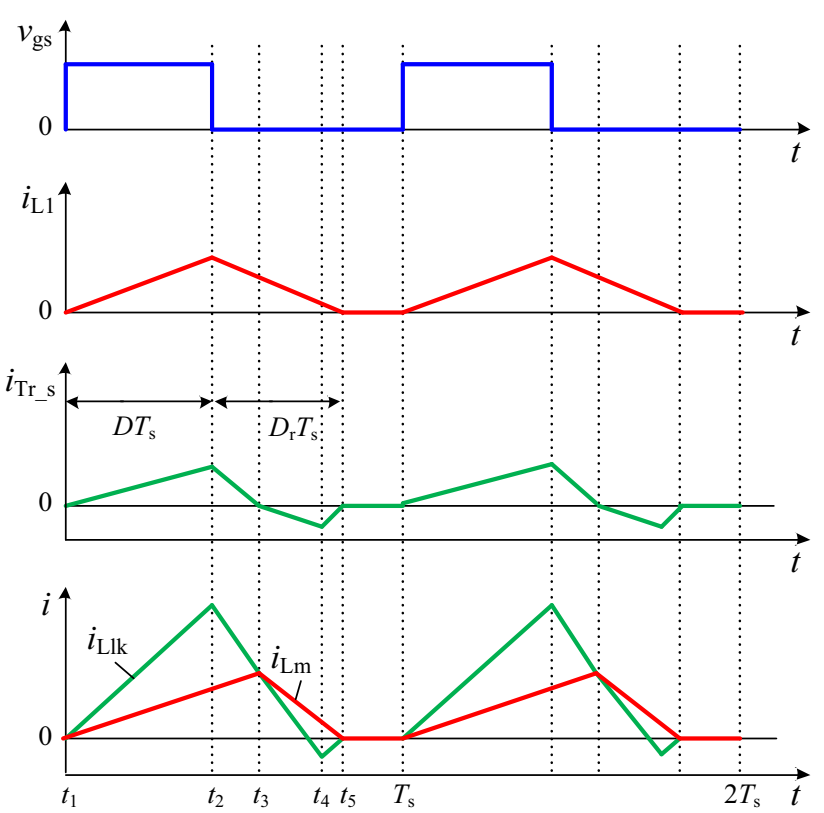

Fig. 10 Key waveforms in DCM

are the same with those in CCM. Here, only Mode 4 and Mode 5 are given in detail.

Mode $4\left[t_{4} \sim t_{5}\right]$ : When $i_{\mathrm{L} 1}=i_{\text {Do1 }}-i_{\mathrm{Llk}}$, the current through $\mathrm{D}_{1}$ decreases to zero and is cut off.

Mode $5\left[t_{5} \sim T_{\mathrm{s}}\right]$ : The currents through $L_{1}$ and $L_{\mathrm{cp}}$ are zero, and $C_{\mathrm{o} 1}$ and $C_{\mathrm{o} 2}$ are in series to supply the load.

\subsection{Voltage gain of CCM}

As the leakage inductor is much smaller compared with the magnetizing inductor, the duration of Modes 2 and 4 in Fig. 8 are relatively short. Thus, the leakage inductor is neglected here, to simplify the analysis.

For steady state, according to the volt-second relationship of $L_{1}$, we have:

$\left(V_{\mathrm{g}}+V_{\mathrm{Ca} 2}\right) D T_{\mathrm{s}}=\left(V_{\mathrm{Ca} 1}-V_{\mathrm{g}}\right)(1-D) T_{\mathrm{s}}$

where $V_{\mathrm{g}}$ is the input voltage; $D$ is the duty cycle of the switch; $T_{\mathrm{s}}$ is the switching period; $V_{\mathrm{a} 1}$ and $V_{\mathrm{a} 2}$ are the average voltages of $C_{\mathrm{a} 1}$ and $C_{\mathrm{a} 2}$, respectively.

Similarly, the volt-second relationship can be applied to $L_{\mathrm{m}}$, then we have:

$V_{\mathrm{Ca} 1} D T_{\mathrm{s}}=V_{\mathrm{Ca} 2}(1-D) T_{\mathrm{s}}$

According to (1) and (2), $V_{\mathrm{Ca} 1}, V_{\mathrm{Ca} 2}$ can be derived as:

$V_{\mathrm{Ca} 1}=\frac{(1-D) V_{\mathrm{g}}}{1-2 D}$

$V_{\mathrm{Ca} 2}=\frac{D V_{\mathrm{g}}}{1-2 D}$

Referring to Fig. 9c, the voltage of $C_{\mathrm{o} 1}$ equals the voltage sum of $C_{\mathrm{a} 1}$ and $C_{\mathrm{a} 2}$. 


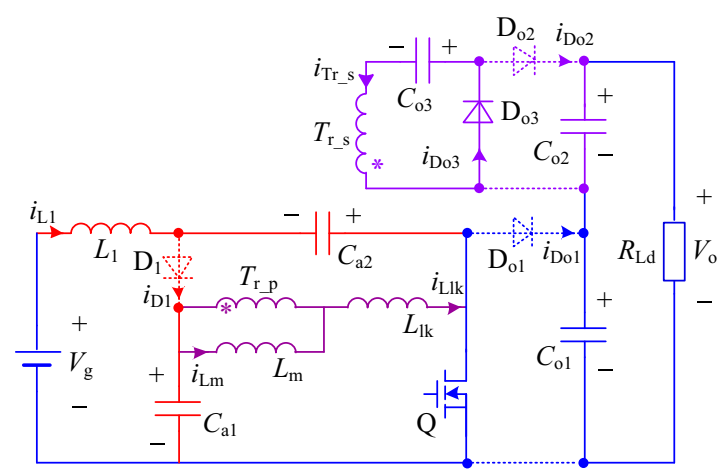

(a) Mode $1\left[t_{1} \sim t_{2}\right]$

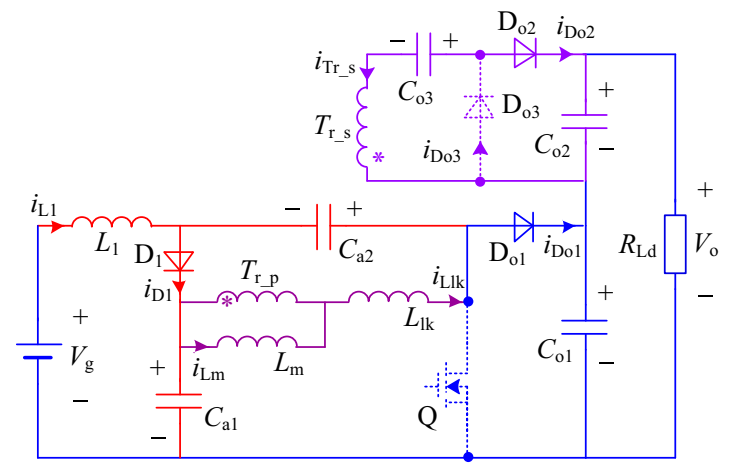

(c) Mode $3\left[t_{3} \sim t_{4}\right]$

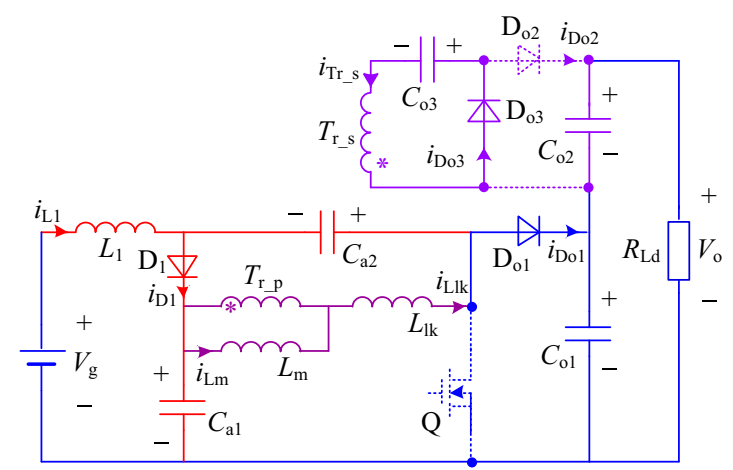

(b) Mode $2\left[t_{2} \sim t_{3}\right]$

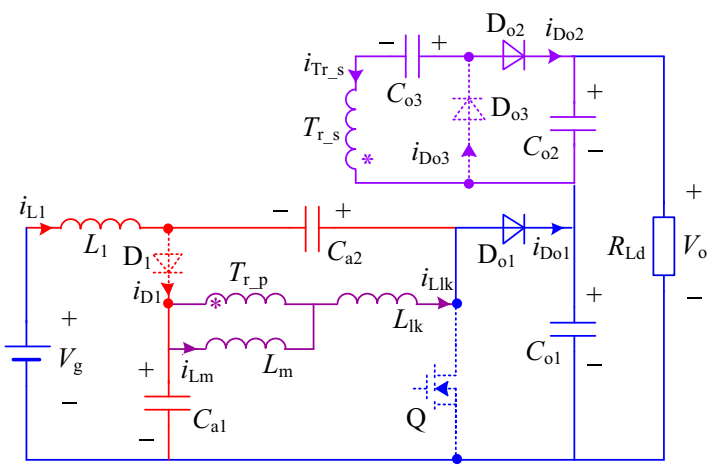

(d) Mode $4\left[t_{4} \sim t_{5}\right]$

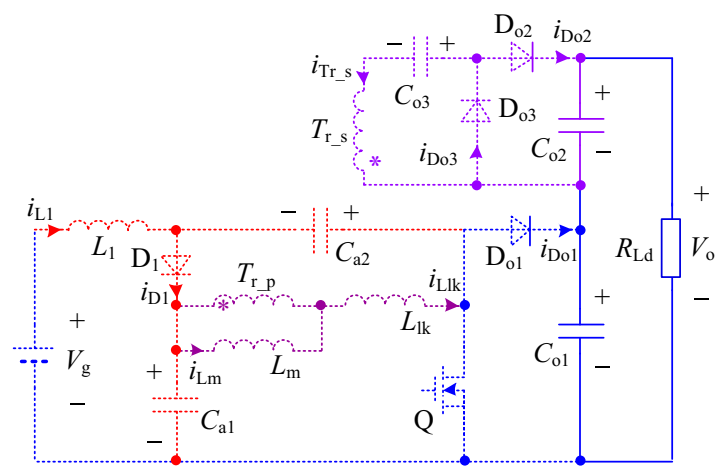

(e) Mode $5\left[t_{5} \sim T_{\mathrm{s}}\right]$

Fig. 11 Operating modes in DCM

$V_{\mathrm{Co} 1}=V_{\mathrm{Ca} 1}+V_{\mathrm{Ca} 2}=\frac{V_{\mathrm{g}}}{1-2 D}$

The voltage of $C_{03}$ can be expressed as:

$V_{\mathrm{Co} 3}=\frac{N_{\mathrm{sp}}(1-D) V_{\mathrm{g}}}{1-2 D}$

where $N_{\mathrm{sp}}=N_{\mathrm{s}} / N_{\mathrm{p}} ; N_{\mathrm{s}}$ is the secondary winding turns; $N_{\mathrm{p}}$ is the primary winding turns.

The voltage of $C_{\mathrm{o} 2}$ is:

$V_{\mathrm{Co} 2}=\frac{N_{\mathrm{sp}} D V_{\mathrm{g}}}{1-2 D}+V_{\mathrm{Co} 3}=\frac{N_{\mathrm{sp}} V_{\mathrm{g}}}{1-2 D}$

Combing (5) and (7), the output voltage is:
$V_{\mathrm{o}}=V_{\mathrm{Co} 1}+V_{\mathrm{Co} 2}=\frac{\left(N_{\mathrm{sp}}+1\right) V_{\mathrm{g}}}{1-2 D}$

Referring to Fig. 9a and c, the voltage stresses of $Q, D_{1}$ and $\mathrm{D}_{\mathrm{o} 1}$ equal $V_{\mathrm{Co} 1}$, which are much smaller than the output voltage. And it is beneficial for improving the efficiency of the converter.

\subsection{Voltage gain of DCM}

To simplify the analysis, an assumption is made that the leakage inductor is neglected. Thus, Mode 2 and Mode 4 
are neglected as well. Then only Mode 1, Mode 3 and Mode 5 need to be considered.

For steady state, applying the volt-second balance principle to $L_{1}$ and $L_{\mathrm{m}}$, we have:

$\left(V_{\mathrm{g}}+V_{\mathrm{Ca} 2}\right) D T_{\mathrm{s}}=\left(V_{\mathrm{Ca} 1}-V_{g}\right) D_{\mathrm{r}} T_{\mathrm{s}}$

$V_{\mathrm{Ca} 1} D T_{\mathrm{s}}=V_{\mathrm{Ca} 2} D_{\mathrm{r}} T_{\mathrm{s}}$

where $D_{\mathrm{r}} T_{\mathrm{s}}=t_{4}-t_{1}$.

Referring to Fig. 11, we have:

$V_{\mathrm{Co} 1}=V_{\mathrm{Ca} 1}+V_{\mathrm{Ca} 2}$

$V_{\mathrm{Co} 3}=N_{\mathrm{sp}} V_{\mathrm{Ca} 1}$

$V_{\mathrm{Co} 2}=V_{\mathrm{Co} 3}+N_{\mathrm{sp}} V_{\mathrm{Ca} 2}=N_{\mathrm{sp}}\left(V_{\mathrm{Ca} 1}+V_{\mathrm{Ca} 2}\right)$

$V_{\mathrm{o}}=V_{\mathrm{Co} 1}+V_{\mathrm{Co} 2}=\left(N_{\mathrm{sp}}+1\right) V_{\mathrm{Co} 1}$

Combining (9), (10) and (11), we can derive:

$V_{\mathrm{Ca} 1}=\frac{V_{\mathrm{Co} 1}+V_{\mathrm{g}}}{2}$

$V_{\mathrm{Ca} 2}=\frac{V_{\mathrm{Co} 1}-V_{\mathrm{g}}}{2}$

$D_{\mathrm{r}}=\frac{V_{\mathrm{Co} 1}+V_{\mathrm{g}}}{V_{\mathrm{Co} 1}-V_{\mathrm{g}}} D$

Thus, the average current of $L_{1}$ can be derived:

$$
\begin{aligned}
I_{\mathrm{L} 1 \_ \text {avg }} & =\frac{V_{\mathrm{g}}+V_{\mathrm{Ca} 2}}{L_{1}} D T_{\mathrm{s}} \frac{D+D_{\mathrm{r}}}{2} \\
& =\frac{V_{\mathrm{g}}+V_{\mathrm{Co} 1}}{2 L_{1}} D T_{\mathrm{s}} \frac{V_{\mathrm{Co} 1} D}{V_{\mathrm{Co} 1}-V_{\mathrm{g}}}
\end{aligned}
$$

If the power loss is neglected, the input average current is:

$I_{\mathrm{L} 1 \_ \text {avg }}=\frac{V_{\mathrm{o}} I_{\mathrm{o}}}{V_{\mathrm{g}}}$

Combining (14), (18) and (19), we can derive:

$V_{\mathrm{o}}=\left(N_{\mathrm{sp}}+1\right) V_{\mathrm{g}} \frac{2\left(N_{\mathrm{sp}}+1\right) I_{\mathrm{o}} L_{1}+V_{\mathrm{g}} D^{2} T_{\mathrm{s}}}{2\left(N_{\mathrm{sp}}+1\right) I_{\mathrm{o}} L_{1}-V_{\mathrm{g}} D^{2} T_{\mathrm{s}}}$

\subsection{Comparison of high step-up converters}

Table 1 gives the comparison of the proposed converter with state-of-art high step-up converters adopting coupled inductor [31-35]. Fig. 12 gives the curves of the voltage gains in Table 1, where $N_{\text {sp }}$ is selected as 4 . As seen, the proposed configuration in Fig. 6b has larger voltage gain than the other high step-up converters with the same duty cycle and reaches a considerable value although the duty cycle has not been close to 0.5. As shown in Fig. 6b, since the coupled inductor replaces $L_{1}$ in Fig. 5 rather than $L_{2}$ on the input side, the input current is continuous, which is beneficial for the lifetime of PV and fuel cell. As a consequence, the voltage stress of $\mathrm{Q}$ in the proposed converter is a little larger.

\section{Experiment verification}

To verify the effectiveness of the proposed configurations in Figs. 5 and $6 \mathrm{~b}$, two prototypes are fabricated in the lab for contrast with the following specifications:

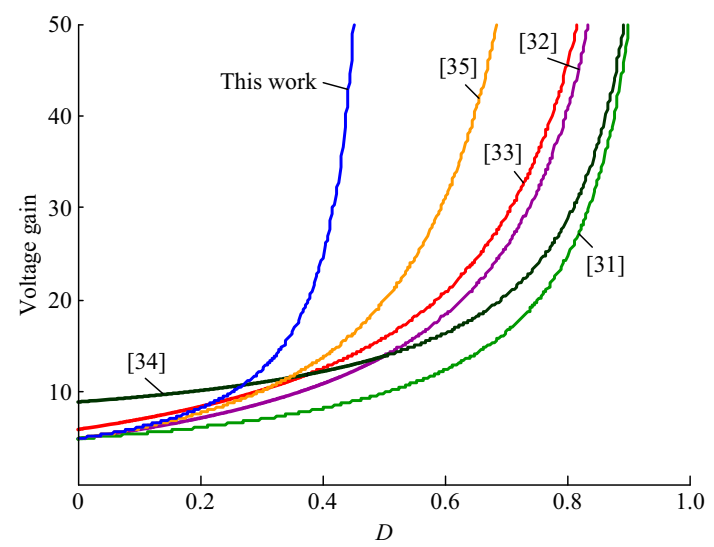

Fig. 12 Comparison of voltage gain

\begin{tabular}{|c|c|c|c|c|c|c|}
\hline Parameter & This work & {$[31]$} & {$[32]$} & [33] & {$[34]$} & {$[35]$} \\
\hline Voltage gain & $\frac{1+N_{\mathrm{sp}}}{1-2 D}$ & $\frac{1+N_{\mathrm{sp}}}{1-D}$ & $\frac{1+N_{\mathrm{sp}}+N_{\mathrm{sp}} D}{1-D}$ & $\frac{2+N_{\mathrm{sp}}+N_{\mathrm{sp}} D}{1-D}$ & $\frac{1+2 N_{\mathrm{sp}}-N_{\mathrm{sp}} D}{1-D}$ & $\frac{1+N_{\mathrm{sp}}}{(1-D)^{2}}$ \\
\hline MOSFET & 1 & 2 & 1 & 1 & 2 & 1 \\
\hline Diode & 4 & 2 & 4 & 4 & 3 & 5 \\
\hline Voltage stress of MOSFET & $\frac{V_{\mathrm{o}}}{1+N_{\mathrm{sp}}}$ & $\frac{V_{\mathrm{o}}}{1+N_{\mathrm{sp}}}$ & $\frac{V_{\mathrm{o}}}{1+N_{\mathrm{sp}}+N_{\mathrm{sp}} D}$ & $\frac{V_{\mathrm{o}}}{2+N_{\mathrm{sp}}+N_{\mathrm{sp}} D}$ & $\frac{V_{\mathrm{o}}}{1+2 N_{\mathrm{sp}}-N_{\mathrm{sp}} D}$ & $\frac{V_{\mathrm{o}}}{1+N_{\mathrm{sp}}}$ \\
\hline Input current & Continuous & Discontinuous & Discontinuous & Discontinuous & Discontinuous & Continuous \\
\hline Input current ripple & Small & Large & Large & Large & Large & Small \\
\hline Magnetic component & 2 & 1 & 1 & 1 & 1 & 2 \\
\hline Capacitor & 5 & 3 & 4 & 4 & 4 & 4 \\
\hline
\end{tabular}

Table 1 Comparison of high step-up converters 
1) Input voltage $V_{\mathrm{g}}: 25-45 V_{\mathrm{dc}}$;

2) Output voltage $V_{\mathrm{o}}: 380 V_{\mathrm{dc}}$;

3) Switching frequency $f_{\mathrm{s}}: 100 \mathrm{kHz}$;

4) Maximal output power $P_{\mathrm{o}}: 300 \mathrm{~W}$.

\subsection{Parameter design}

As the design progress of the converters in Figs. 5 and $6 \mathrm{~b}$ are similar, the topology as shown in Fig. $6 \mathrm{~b}$ is taken as an example to design the parameter.

Prior to the design procedure of capacitors and inductors, an assumption is made to simplify the analysis. Since the leakage inductor is relatively small compared with the magnetizing inductor, its influence can be ignored.

1) Design of coupled inductor $L_{\mathrm{cp}}$

As shown in Table 1, the voltage stress of the switch decreases with the increase of $N_{\text {sp. }}$ However, higher $N_{\mathrm{sp}}$ would increase the current stress of the switch. Thus, a trade-off design should be considered between the voltage stress and current stress of the switch. Here, we prefer the voltage stress lower than $100 \mathrm{~V}$, and the resultant $N_{\mathrm{sp}}$ is 4.

Referring to Fig. 7, according to Kirchhoff's circuit laws, we have:

$$
\begin{aligned}
i_{\mathrm{L} 1} & =i_{\mathrm{D} 1}-i_{\mathrm{Ca} 2}=i_{\mathrm{Ca} 1}+i_{\mathrm{Lm}}+i_{\mathrm{Tr} \_\mathrm{p}}-i_{\mathrm{Ca} 2} \\
& =i_{\mathrm{Ca} 1}+i_{\mathrm{Lm}}+N_{\mathrm{sp}} i_{\mathrm{Tr} \_\mathrm{s}}-i_{\mathrm{Ca} 2} \\
& =i_{\mathrm{Ca} 1}+i_{\mathrm{Lm}}+N_{\mathrm{sp}} i_{\mathrm{Co} 3}-i_{\mathrm{Ca} 2}
\end{aligned}
$$

Based on the charge balance principle, the average currents of capacitors, $I_{\mathrm{Ca} 1 \_a v g}, I_{\mathrm{Ca} 2 \_a v g}$, and $I_{\mathrm{Co} 3 \_a v g}$ are zero. Thus, the average current of $L_{1}$ equals the average current of $L_{\mathrm{m}}$, and we have:

$I_{\mathrm{L} 1 \_ \text {avg }}=I_{\mathrm{Lm} \_ \text {avg }}=P_{\mathrm{o}} / V_{\mathrm{g}}$

Setting the maximum current ripple of $L_{\mathrm{m}}$ is $30 \%$ of the maximum average current, then we have:

$\Delta i_{\mathrm{Lm}}=\frac{V_{\mathrm{Ca} 1} D T_{\mathrm{s}}}{L_{\mathrm{m}}}=\frac{V_{\mathrm{g}}(1-D) D T_{\mathrm{s}}}{(1-2 D) L_{\mathrm{m}}} \leq 30 \% I_{\mathrm{Lm} \_ \text {avg }}$

Substituting (22) into (23), yields:

$L_{\mathrm{m}} \geq \frac{V_{\mathrm{g}}^{2}(1-D) D T_{\mathrm{s}}}{30 \%(1-2 D) P_{\mathrm{o}}}$

When $V_{\mathrm{g}}=25 \mathrm{~V}$, the right part of (24) reaches the maximum value. Then we have $L_{\mathrm{m}}=50 \mu \mathrm{H}$.

2) Design of inductor $L_{1}$

Likewise, the maximum current ripple of $L_{1}$ can be expressed as:

$$
\Delta i_{\mathrm{L} 1}=\frac{\left(V_{\mathrm{g}}+V_{\mathrm{Ca} 2}\right) D T_{\mathrm{s}}}{L_{1}}=\frac{V_{\mathrm{g}}(1-D) D T_{\mathrm{s}}}{(1-2 D) L_{1}} \leq 30 \% I_{\mathrm{L} 1 \_ \text {avg }}
$$

Substituting (22) into (25), yields:

$L_{1} \geq \frac{V_{\mathrm{g}}^{2}(1-D) D T_{\mathrm{s}}}{30 \%(1-2 D) P_{\mathrm{o}}}$

When $V_{\mathrm{g}}=25 \mathrm{~V}$, the right part of (26) reaches the maximum value. Then we have $L_{\mathrm{m}}=50 \mu \mathrm{H}$.

3) Design of auxiliary capacitor $C_{\mathrm{a} 1}$ and $C_{\mathrm{a} 2}$

The capacitor $C_{\mathrm{a} 1}$ and $C_{\mathrm{a} 2}$ can be derived according to the voltage ripple $\Delta V_{\mathrm{Ca} 1}$ and $\Delta V_{\mathrm{Ca} 2}$ :

$C_{\mathrm{a} 1}=\frac{\int_{0}^{D T_{\mathrm{s}}} i_{\mathrm{Ca} 1} \mathrm{~d} t}{\Delta V_{\mathrm{Ca} 1}}$

$C_{\mathrm{a} 2}=\frac{\int_{0}^{D T_{\mathrm{s}}} i_{\mathrm{Ca} 2} \mathrm{~d} t}{\Delta V_{\mathrm{Ca} 2}}$

Referring to Fig. 9a, during the turn on interval, we have:

$i_{\mathrm{Ca} 1}=i_{\mathrm{Lm}}+N_{\mathrm{sp}} i_{\mathrm{Tr} \_\mathrm{s}}=i_{\mathrm{Lm}}+N_{\mathrm{sp}} i_{\mathrm{Do} 3}$

$i_{\mathrm{Ca} 2}=i_{\mathrm{L} 1}$

Since the average currents of $C_{\mathrm{o} 2}$ and $C_{\mathrm{o} 3}$ are zero, the average current through $\mathrm{D}_{\mathrm{o} 3}$ equals to $I_{\mathrm{o}}$. Then we have:

$\int_{0}^{D T_{\mathrm{s}}} i_{\text {Do3 }} \mathrm{d} t=I_{\mathrm{o}} T_{\mathrm{s}}$

Substituting (29), (30) and (31) into (27) and (28), yields:

$C_{\mathrm{a} 1}=\frac{I_{\mathrm{Lm}{ }_{\mathrm{avg}}} D T_{\mathrm{s}}}{\Delta V_{\mathrm{Ca} 1}}+\frac{N_{\mathrm{sp}} I_{\mathrm{o}} T_{\mathrm{s}}}{\Delta V_{\mathrm{Ca} 1}}=\frac{P_{\mathrm{o}} D T_{\mathrm{s}}}{V_{\mathrm{g}} \Delta V_{\mathrm{Ca} 1}}+\frac{N_{\mathrm{sp}} I_{\mathrm{o}} T_{\mathrm{s}}}{\Delta V_{\mathrm{Ca} 1}}$

$C_{\mathrm{a} 2}=\frac{I_{\mathrm{L} 1 \_\mathrm{avg}} D T_{\mathrm{s}}}{\Delta V_{\mathrm{Ca} 2}}=\frac{P_{\mathrm{o}} D T_{\mathrm{s}}}{V_{\mathrm{g}} \Delta V_{\mathrm{Ca} 2}}$

Setting the voltage ripple is lower than $5 \%$ of the maximum average voltage, we have $C_{\mathrm{a} 1}=24 \mu \mathrm{F}, C_{\mathrm{a} 2}=32 \mu \mathrm{F}$.

4) Design of output capacitor $C_{\mathrm{o} 1}, C_{\mathrm{o} 2}$ and $C_{\mathrm{o} 3}$

Likewise, the output capacitors can be derived as:

$C_{\mathrm{o} 1}=\frac{\int_{0}^{D T_{\mathrm{s}}} i_{\mathrm{Co} 1} \mathrm{~d} t}{\Delta V_{\mathrm{Co} 1}}$

$C_{\mathrm{o} 2}=\frac{\int_{0}^{D T_{\mathrm{s}}} i_{\mathrm{Co} 2} \mathrm{~d} t}{\Delta V_{\mathrm{Co} 2}}$

$C_{\mathrm{o} 3}=\frac{\int_{0}^{D T_{\mathrm{s}}} i_{\mathrm{Co} 3} \mathrm{~d} t}{\Delta V_{\mathrm{Co} 3}}$

Referring to Fig. 9a, during the turn on interval, we have:

$i_{\mathrm{Co} 1}=i_{\mathrm{Co} 2}=I_{\mathrm{o}}$ 
$i_{\mathrm{Co} 3}=i_{\text {Do3 }}$

Substituting (31), (37) and (38) into (34), (35) and (36), yields:

$C_{\mathrm{o} 1}=\frac{I_{\mathrm{o}} D T_{\mathrm{s}}}{\Delta V_{\mathrm{Co} 1}}$

$C_{\mathrm{o} 2}=\frac{I_{\mathrm{o}} D T_{\mathrm{s}}}{\Delta V_{\mathrm{Co} 2}}$

$C_{\mathrm{o} 3}=\frac{I_{\mathrm{o}} T_{\mathrm{s}}}{\Delta V_{\mathrm{Co} 3}}$

Since $C_{\mathrm{o} 1}, C_{\mathrm{o} 2}$ is placed on the output side, the voltage ripples of $C_{\mathrm{o} 1}$ and $C_{\mathrm{o} 2}$ are limited to a smaller scale. If the voltage ripples of $C_{\mathrm{o} 1}$ and $C_{\mathrm{o} 2}$ are limited to $1 \%$ of the respective maximum average voltage, and the voltage ripple of $C_{03}$ is limited to $5 \%$ of the maximum average voltage, we have $C_{\mathrm{o} 1}=4 \mu \mathrm{F}, C_{\mathrm{o} 2}=3 \mu \mathrm{F}, C_{\mathrm{o} 3}=3 \mu \mathrm{F}$.

\section{5) Switch $Q$}

The voltage stress of the switch is $V_{\mathrm{o}} /\left(N_{\mathrm{sp}}+1\right)$. When $\mathrm{Q}$ is turned on, the current of the switch $i_{\mathrm{Q}}$ can be expressed as:

$$
\begin{aligned}
i_{\mathrm{Q}} & =i_{\mathrm{L} 1}+i_{\mathrm{Lm}}+N_{\mathrm{sp}} i_{\text {Do3 }} \\
& =\frac{2 V_{\mathrm{g}}(1-D) t}{(1-2 D) L_{1}}+\frac{2 P_{\mathrm{o}}}{V_{\mathrm{g}}}-\frac{V_{\mathrm{g}}(1-D) D T_{\mathrm{s}}}{(1-2 D) L_{1}}+\frac{2 N_{\mathrm{sp}} I_{\mathrm{o}} t}{D D T_{\mathrm{s}}}
\end{aligned}
$$

When $V_{\mathrm{g}}=25 \mathrm{~V}$, the RMS current of $\mathrm{Q}$ reaches its maximum value $19.8 \mathrm{~A}$.

6) Diode $D_{1}, D_{o 1}, D_{\mathrm{o} 2}$ and $D_{03}$

The voltage stresses of $\mathrm{D}_{1}$ and $\mathrm{D}_{\mathrm{o} 1}$ are $V_{\mathrm{o}} /\left(N_{\mathrm{sp}}+1\right)$, and the voltage stresses of $\mathrm{D}_{\mathrm{o} 2}$ and $\mathrm{D}_{\mathrm{o} 3}$ are $N_{\mathrm{sp}} V_{\mathrm{o}} /\left(N_{\mathrm{sp}}+1\right)$.

The currents through $\mathrm{D}_{\mathrm{o} 2}$ and $\mathrm{D}_{\mathrm{o} 3}$ can be expressed as:

$$
\begin{aligned}
& i_{\text {Do2 }}= \begin{cases}0 & t \in\left[0, D T_{\mathrm{s}}\right] \\
\frac{2 I_{\mathrm{o}}\left(t-D T_{\mathrm{s}}\right)}{(1-D)(1-D) T_{\mathrm{s}}} & t \in\left[D T_{\mathrm{s}}, T_{\mathrm{s}}\right]\end{cases} \\
& i_{\text {Do3 }}= \begin{cases}\frac{2 I_{\mathrm{o}} t}{D D T_{\mathrm{s}}} & t \in\left[0, D T_{\mathrm{s}}\right] \\
0 & t \in\left[D T_{\mathrm{s}}, T_{\mathrm{s}}\right]\end{cases}
\end{aligned}
$$

According to Fig. 9c, we have:

$$
\begin{aligned}
& v_{\mathrm{Ca} 1}+v_{\mathrm{Ca} 2}=v_{\mathrm{Co} 1} \\
& \frac{\mathrm{d} v_{\mathrm{Ca} 1}}{\mathrm{~d} t}+\frac{\mathrm{d} v_{\mathrm{Ca} 2}}{\mathrm{~d} t}=\frac{\mathrm{d} v_{\mathrm{Co} 1}}{\mathrm{~d} t} \\
& \left\{\begin{array}{l}
C_{\mathrm{a} 1} \frac{\mathrm{d} v_{\mathrm{Ca} 1}}{\mathrm{~d} t}+C_{\mathrm{o} 1} \frac{\mathrm{d} v_{\mathrm{Co} 1}}{\mathrm{~d} t}+I_{\mathrm{o}}=i_{\mathrm{L} 1} \\
C_{\mathrm{a} 2} \frac{\mathrm{d} v_{\mathrm{Ca} 2}}{\mathrm{~d} t}+C_{\mathrm{o} 1} \frac{\mathrm{d} v_{\mathrm{Co} 1}}{\mathrm{~d} t}+N_{\mathrm{sp}} i_{\mathrm{Do} 2}+I_{\mathrm{o}}=i_{\mathrm{Lm}}
\end{array}\right.
\end{aligned}
$$

where $v_{\mathrm{Ca} 1}, v_{\mathrm{Ca} 2}$ and $v_{\mathrm{Co} 1}$ are the instantaneous voltages of $C_{\mathrm{a} 1}, C_{\mathrm{a} 2}$ and $C_{\mathrm{o} 1}$, respectively.

Combining (46) and (47), the currents through $\mathrm{D}_{1}$ and $\mathrm{D}_{\mathrm{o} 1}$ can be expressed as:

$$
\begin{aligned}
i_{\mathrm{D} 1}= & i_{\mathrm{L} 1}+C_{\mathrm{a} 2} \frac{\mathrm{d} v_{\mathrm{Ca} 2}}{\mathrm{~d} t}=\frac{\left(C_{\mathrm{a} 1} C_{\mathrm{a} 2}+C_{\mathrm{a} 2} C_{\mathrm{o} 1}\right)\left(i_{\mathrm{Lm}}-N_{\mathrm{sp}} i_{\mathrm{Do} 2}\right)}{C_{\mathrm{a} 1} C_{\mathrm{a} 2}+C_{\mathrm{a} 1} C_{\mathrm{o} 1}+C_{\mathrm{a} 2} C_{\mathrm{o} 1}} \\
& +\frac{+\left(C_{\mathrm{a} 1} C_{\mathrm{a} 2}+C_{\mathrm{a} 1} C_{\mathrm{o} 1}\right) i_{\mathrm{L} 1}-C_{\mathrm{a} 1} C_{\mathrm{a} 2} I_{\mathrm{o}}}{C_{\mathrm{a} 1} C_{\mathrm{a} 2}+C_{\mathrm{a} 1} C_{\mathrm{o} 1}+C_{\mathrm{a} 2} C_{\mathrm{o} 1}}
\end{aligned}
$$

$$
\begin{aligned}
& i_{\mathrm{Do} 1}=I_{\mathrm{o}}+C_{\mathrm{o} 1} \frac{\mathrm{d} v_{\mathrm{Co} 1}}{\mathrm{~d} t}= \\
& \quad \frac{C_{\mathrm{a} 1} C_{\mathrm{a} 2} I_{\mathrm{o}}+C_{\mathrm{a} 1} C_{\mathrm{o} 1}\left(i_{\mathrm{Lm}}-N_{\mathrm{sp}} i_{\mathrm{Do} 2}\right)+C_{\mathrm{a} 2} C_{\mathrm{o} 1} i_{\mathrm{Lb}}}{C_{\mathrm{a} 1} C_{\mathrm{a} 2}+C_{\mathrm{a} 1} C_{\mathrm{o} 1}+C_{\mathrm{a} 2} C_{\mathrm{o} 1}}
\end{aligned}
$$

According to (43), (44), (48) and (49), the current stresses of $\mathrm{D}_{1}, \mathrm{D}_{\mathrm{o} 1}, \mathrm{D}_{\mathrm{o} 2}$ and $\mathrm{D}_{\mathrm{o} 3}$ can be calculated.

\subsection{Experiment results}

The main components used in the prototypes are listed in the following.

High step-up converter adopting auxiliary capacitor:

1) Q: IPW65R045C7;

2) $\mathrm{D}_{1}:$ IDW20G65C5, $\mathrm{D}_{\mathrm{o}}: \mathrm{C} 3 \mathrm{D} 10060 \mathrm{~A}$;

3) $L_{1}: 263 \mu \mathrm{H}, L_{2}: 263 \mu \mathrm{H}$;

4) $C_{\mathrm{a} 1}: 5.6 \mu \mathrm{F}, C_{\mathrm{a} 2}: 6.8 \mu \mathrm{F}, C_{\mathrm{f}}: 220 \mu \mathrm{F}$.

High step-up converter adopting auxiliary capacitor and coupled inductor:

1) Q: IPP110N20N3G;

2) $\mathrm{D}_{1}:$ STPS20120C, $\mathrm{D}_{\mathrm{o} 1}:$ STPS10120C;

3) $\mathrm{D}_{\mathrm{o} 2}: \mathrm{C} 3 \mathrm{D} 10060 \mathrm{~A}, \mathrm{D}_{\mathrm{o} 3}: \mathrm{C} 3 \mathrm{D} 10060 \mathrm{~A}$;

4) $L_{1}: 50 \mu \mathrm{H}, L_{\mathrm{m}}: 50 \mu \mathrm{H}, N_{\mathrm{sp}}: 4$;

5) $C_{\mathrm{a} 1}: 24 \mu \mathrm{F}, C_{\mathrm{a} 2}: 32 \mu \mathrm{F}, C_{\mathrm{f}}: 220 \mu \mathrm{F}$;

6) $C_{\mathrm{o} 1}: 4 \mu \mathrm{F}, C_{\mathrm{o} 2}: 3 \mu \mathrm{F}, C_{\mathrm{o} 3}: 3 \mu \mathrm{F}$.

where $C_{\mathrm{f}}$ is used to realize the power decoupling if high step-up converter is cascaded with an inverter. And it is parallel with $C_{\mathrm{o} 1}$ and $C_{\mathrm{o} 2}$ in the high step-up converter adopting auxiliary capacitor and coupled inductor.

The experimental waveforms of high step-up converter based on quasi-Z-source network under different input voltages at full load are shown in Figs. 13 and 14, where $v_{\mathrm{ds}}$ is the drain-source voltage of the switch. As seen in Fig. $14, D_{1}$ and $D_{0}$ conducts simultaneously. It can be explained as follows. Due to the forward recovery phenomenon of $\mathrm{D}_{1}$, the voltage sum of $C_{\mathrm{a} 1}, C_{\mathrm{a} 2}$ and the voltage drop of $\mathrm{D}_{1}$ is larger than the output filter capacitor when the switch is turned off. The voltage difference will drop on ESR of the output filter capacitor and cause a large current through $D_{0}$. As shown in Fig. 14, at the instant of turning off the switch, $v_{\mathrm{ds}}$ is slightly large, and there is a large 


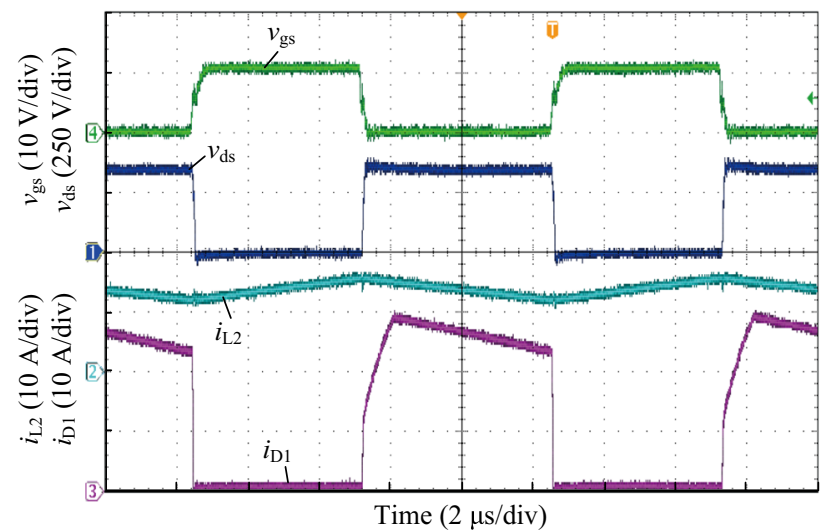

(a) $V_{\mathrm{g}}=25 \mathrm{~V}$

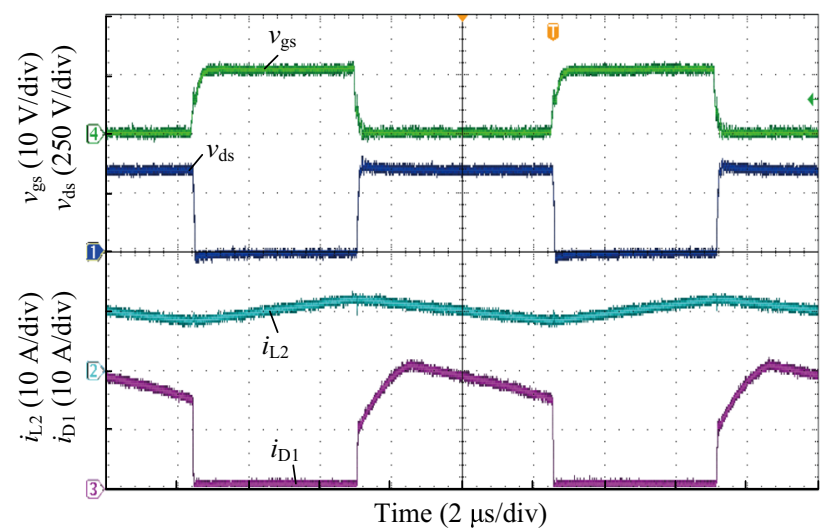

(b) $V_{\mathrm{g}}=36 \mathrm{~V}$

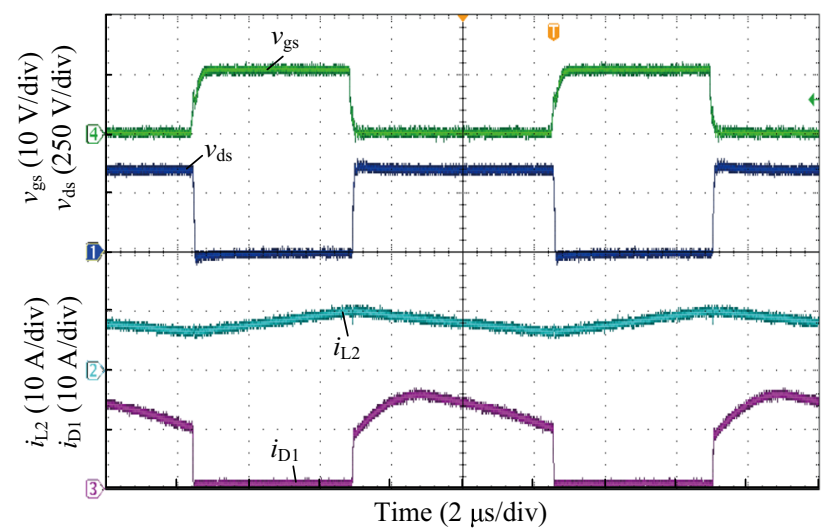

(c) $V_{\mathrm{g}}=45 \mathrm{~V}$

Fig. 13 Experiment waveforms of high step-up converter adopting auxiliary capacitor

current through $\mathrm{D}_{\mathrm{o}}$. Thus, the current supplied by $L_{1}$ to replenish energy for $C_{\mathrm{a} 2}$ is small, and $i_{\mathrm{D} 1}$ is small. With the voltage drop of $D_{1}$ reducing gradually, the difference between $v_{\mathrm{ds}}$ and the voltage of $C_{\mathrm{f}}$ decreases, resulting that $i_{\mathrm{Do}}$ decreases and $i_{\mathrm{D} 1}$ increases. As $C_{\mathrm{a} 1}$ and $C_{\mathrm{a} 2}$ are much smaller than $C_{\mathrm{f}}$, the voltage ripples of $C_{\mathrm{a} 1}$ and $C_{\mathrm{a} 2}$ are larger. Thus, with the voltages of the auxiliary capacitors

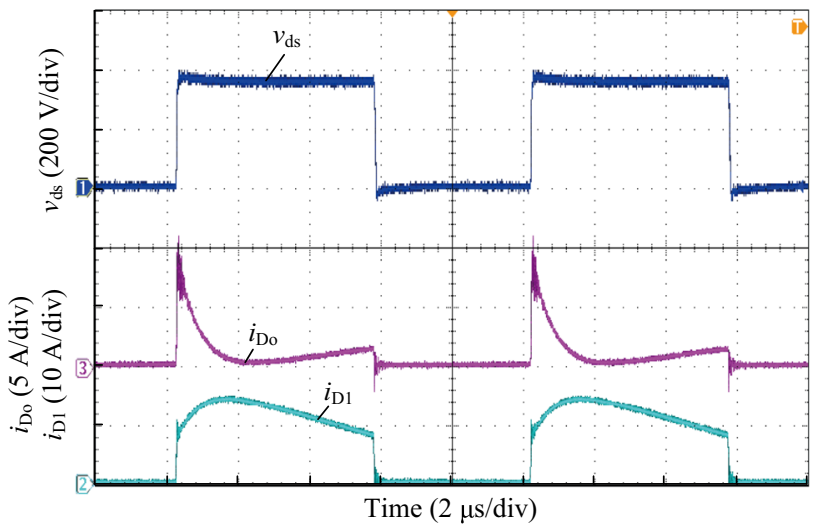

Fig. 14 Experiment waveforms of high step-up converter adopting auxiliary capacitor $\left(V_{\mathrm{g}}=45 \mathrm{~V}, P_{\mathrm{o}}=300 \mathrm{~W}\right)$

increasing, the difference between $v_{\mathrm{ds}}$ and the voltage of $C_{\mathrm{f}}$ increases, leading to $i_{\mathrm{Do}}$ increasing and $i_{\mathrm{D} 1}$ decreasing.

The experimental waveforms of high step-up converter adopting auxiliary capacitor and coupled inductor under different input voltages at full load are shown in Figs. 15 and 16 where $i_{\text {cp_p }}$ is the current of the primary winding, $i_{\mathrm{Do3}}$ is the current of $\mathrm{D}_{\mathrm{o} 3}, v_{\mathrm{D} 1}$ and $v_{\mathrm{Do} 1}$ are the voltages of $\mathrm{D}_{1}$ and $\mathrm{D}_{\mathrm{o} 1}$. According to the theoretical analysis, $i_{\mathrm{Do} 3}$ should rise up from zero when the switch is turned on. However, in the real case, there exist reverse recovery problem for $\mathrm{D}_{\mathrm{o} 2}$ at the instant of turning on the switch. During the time interval of the reverse recovery, the voltage of the secondary winding is clamped by $C_{\mathrm{o} 2}$ and $C_{\mathrm{o} 3}$. The voltage is reflected to the primary side by electromagnetic induction and in series with $C_{\mathrm{a} 1}$ to charge the leakage inductor which leads to the current of the leakage inductor rising up rapidly. After the reverse recovery of $\mathrm{D}_{\mathrm{O} 2}$ is over, the current of the leakage inductor is larger than that of the magnetizing inductor. Thus, $i_{\text {Do3 }}$ rises up from a positive value. The voltage stresses of the switch, $D_{1}$ and $D_{o 1}$ shown in Fig. 16 are much smaller than the output voltage which will reduce the power loss and improve the efficiency.

The dynamic response of high step-up converter adopting auxiliary capacitor and coupled inductor is shown in Fig. 17. The output voltage is regulated in closed loop with single voltage compensator. The experimental result shows that the dynamic performance of the proposed converter is good. The startup waveform $\left(V_{\mathrm{g}}=36 \mathrm{~V}\right.$, $P_{\mathrm{o}}=300 \mathrm{~W}$ ) is shown in Fig. 18, where $v_{\mathrm{o}}$ is the output voltage, and $i_{\mathrm{L} 1}$ is the current of $L_{1}$. As seen, the overshoot of the output voltage is less than $30 \mathrm{~V}$, which is $7.9 \%$ of the steady-state value.

The comparison experiments of the basic boost converter and the cascaded boost converter are also performed. To avoid the instability issue in the cascaded boost converter, the first stage is under open loop control with 


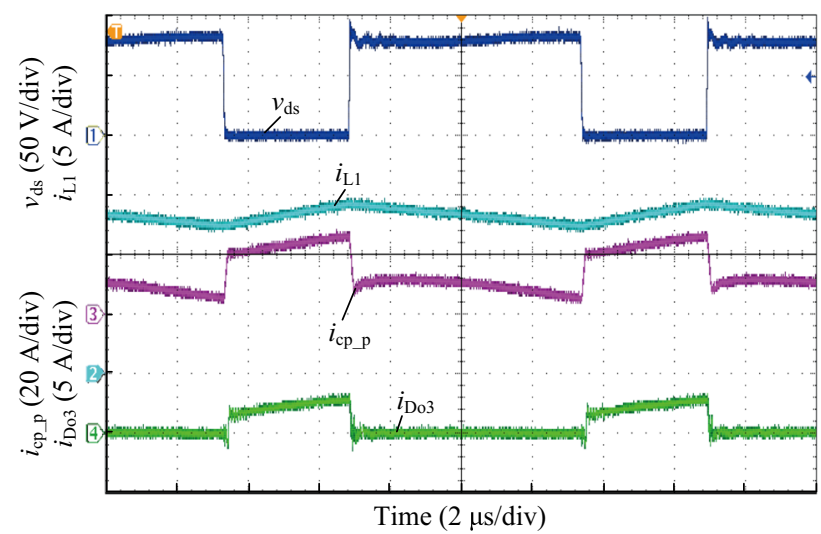

(a) $V_{\mathrm{g}}=25 \mathrm{~V}$

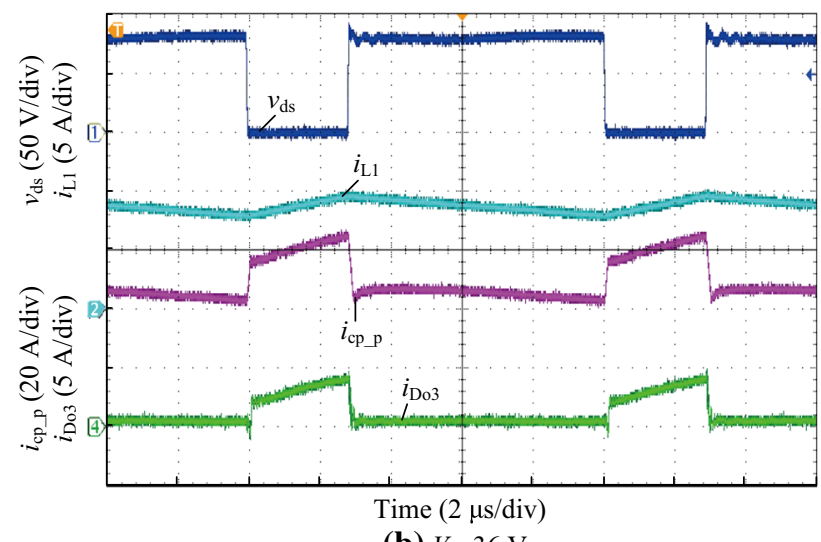

(b) $V_{\mathrm{g}}=36 \mathrm{~V}$

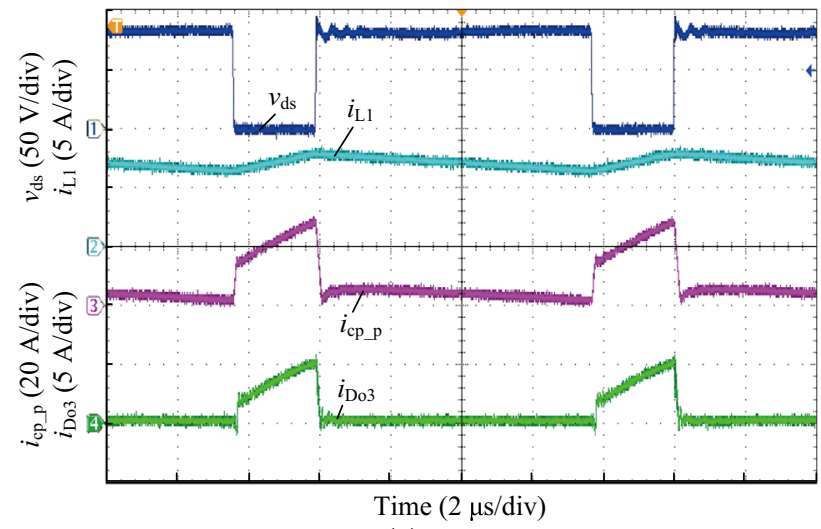

(c) $V_{\mathrm{g}}=45 \mathrm{~V}$

Fig. 15 Experiment waveforms of high step-up converter adopting auxiliary capacitor and coupled inductor

constant voltage gain of 4 . The second stage of the cascaded boost converter regulate the output voltage. The efficiency curves of high step-up converter adopting auxiliary capacitor, high step-up converter adopting auxiliary capacitor and coupled inductor, the basic boost converter, and the cascaded boost converter are shown in Fig. 19. As the conducting period of $\mathrm{D}_{\mathrm{o}}$ in the basic boost converter is extremely short, the current stress is large and the reverse

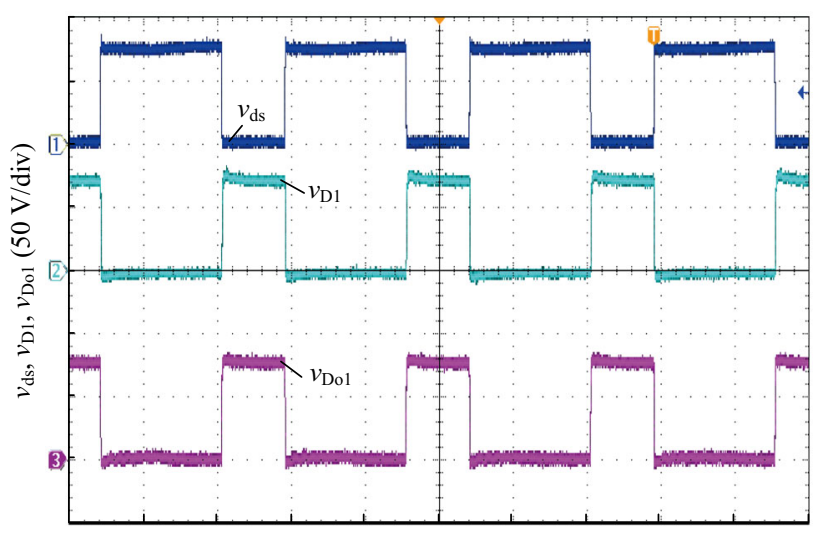

Time $(4 \mu \mathrm{s} / \mathrm{div})$

(a) $V_{\mathrm{g}}=25 \mathrm{~V}$

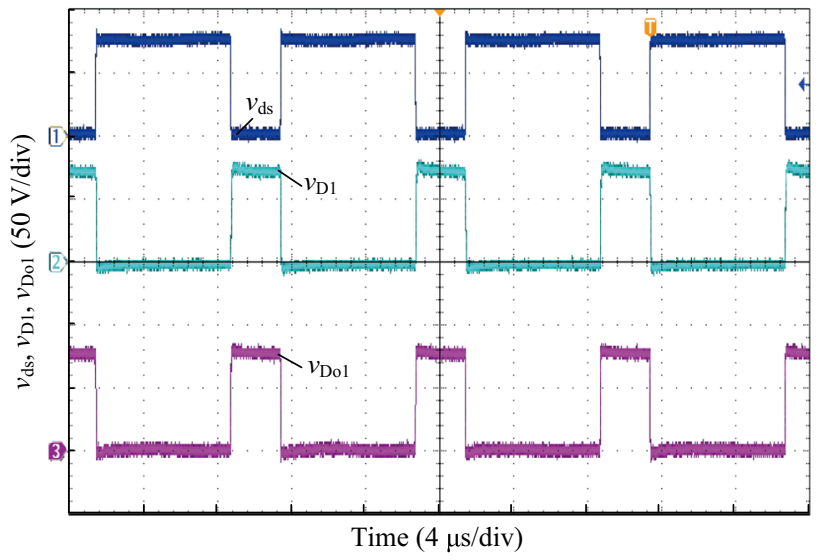

(b) $V_{\mathrm{g}}=36 \mathrm{~V}$

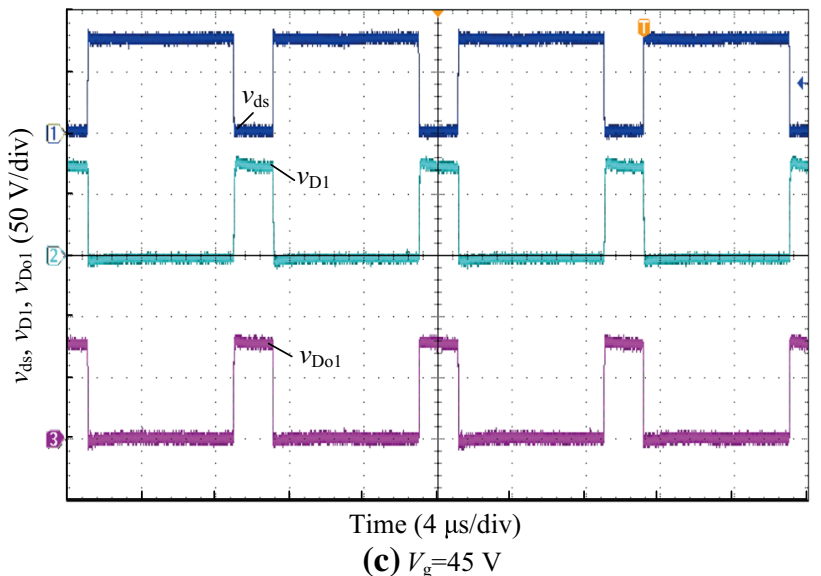

Fig. 16 Voltage stresses of the switch $D_{1}$ and $D_{01}$

recovery problem is severe which leads to a large switching loss of the switch. Thus, the efficiency of the basic boost converter is lower than that of high step-up converter adopting auxiliary capacitor at heavy load as shown in Fig. 19. When the coupled inductor is adopted, the efficiency is further improved. Due to the voltage stresses of the switch, $D_{1}$ and $D_{o 1}$ decreasing, the switching loss can 


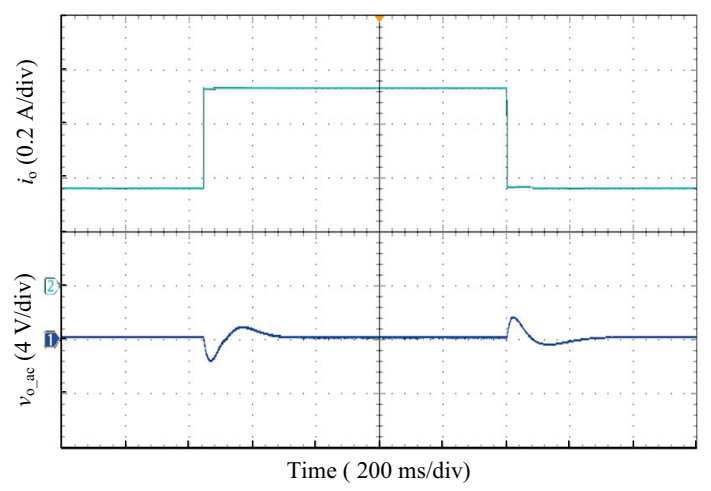

Fig. 17 Dynamic response of high step-up converter adopting auxiliary capacitor and coupled inductor when the load step varies between the full load and the half load

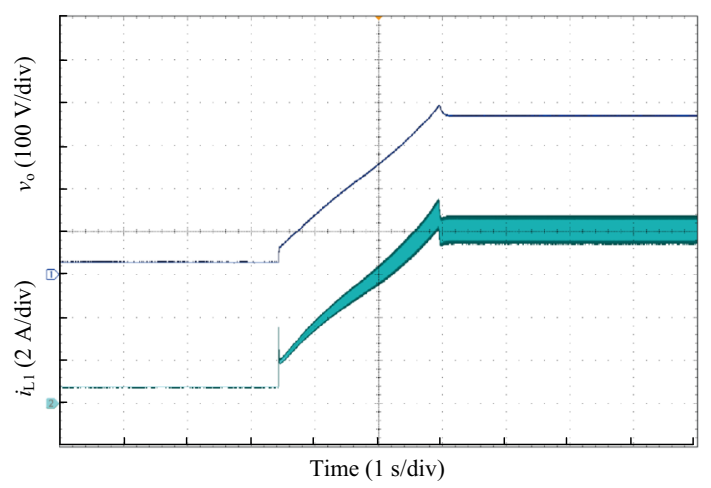

Fig. 18 Startup waveform

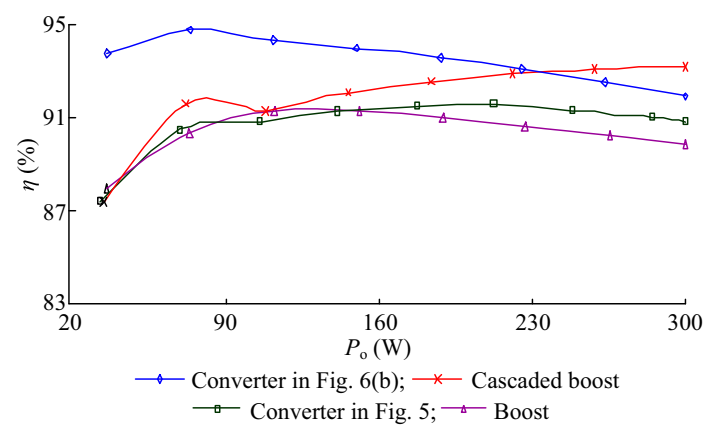

Fig. 19 Efficiency comparison when $V_{\mathrm{g}}=45 \mathrm{~V}$

be reduced effectively and the efficiency is superior to that of the cascaded boost converter over a wide load range.

According to the calculation of the power loss in Appendix A, the estimated efficiency is shown as Fig. 20, which matches the measured efficiency. And the power

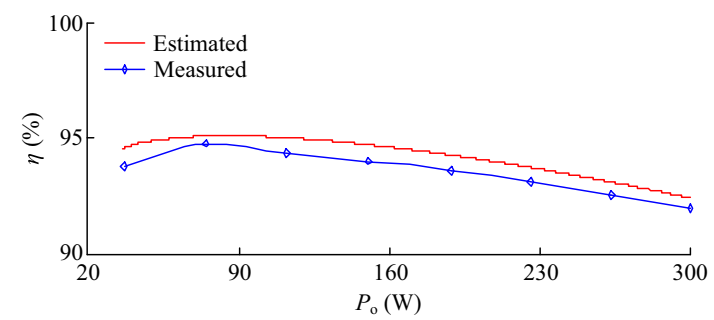

Fig. 20 Estimated efficiency and measured efficiency $\left(V_{\mathrm{g}}=45 \mathrm{~V}\right)$

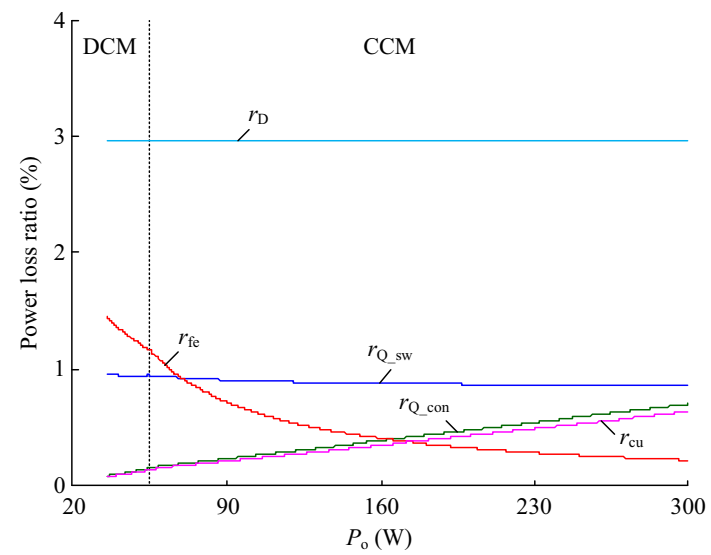

Fig. 21 Power loss ratio $\left(V_{\mathrm{g}}=45 \mathrm{~V}\right)$

loss ratios are given in Fig. 21, where $r_{\mathrm{Q}_{-} \text {sw }}=$ $\left(P_{\mathrm{Q} \_ \text {on }}+P_{\mathrm{Q} \_ \text {off }}\right) / P_{\text {in }}, r_{\mathrm{Q} \_ \text {con }}=P_{\mathrm{Q}_{-} \text {con }} / P_{\text {in }}, r_{\text {fe }}=\left(P_{\mathrm{L} 1_{\_} \text {fe }}+\right.$ $\left.P_{\mathrm{Lcp} \_ \text {fe }}\right) / P_{\text {in }}, \quad r_{\text {cu }}=\left(P_{\text {L1_cu }}+P_{\text {Lcp_cu }}\right) / P_{\text {in }}, \quad r_{\mathrm{D}}=\left(P_{\mathrm{D} 1}+\right.$ $\left.P_{\mathrm{Do1}}+P_{\mathrm{Do2} 2}+P_{\mathrm{Do} 3}\right) / P_{\text {in }}$. As seen, $r_{\mathrm{Q} \_ \text {sw }}$ and $r_{\mathrm{fe}}$ decrease with the increase of the output power, while $r_{\mathrm{Q} \_c o n}$ and $r_{\mathrm{cu}}$ increase with the increase of the output power. Thus, the efficiency increases at light load and decreases at heavy load. And the present of the maximum efficiency depends on the parasitic parameter of the components.

The experiment results indicate that the proposed converters can achieve a higher efficiency and good dynamic performance as well.

\section{Conclusion}

A novel high step-up DC-DC converter adopting auxiliary capacitor and coupled inductor is proposed in this paper. The input current is continuous, and the voltage stress of the power switch is low, which reduces the switching loss. Thus, the efficiency of the converter is improved. The operating mode of the proposed topology is analyzed and an experiment is conducted. The results 
indicate that the converters proposed in this paper can operate steadily and the performance is good.

Acknowledgements This work was supported by Lite-On Technology Corporation.

Open Access This article is distributed under the terms of the Creative Commons Attribution 4.0 International License (http:// creativecommons.org/licenses/by/4.0/), which permits unrestricted use, distribution, and reproduction in any medium, provided you give appropriate credit to the original author(s) and the source, provide a link to the Creative Commons license, and indicate if changes were made.

\section{Appendix A}

The main power losses include the power loss of the switch, the diodes, the inductor and the coupled inductor. According to the parameter design in Section 4, the current stresses of the switch, the diodes, the inductor and the coupled inductor are given, and then the power loss of each component can be calculated as follows.

1) Power loss of the switch $Q$

The power loss of the switch mainly includes the switching loss and the conduction loss. The switching loss can be derived as:

$P_{\mathrm{Q} \_ \text {on }}=\frac{f_{\mathrm{s}} R_{\mathrm{g}} V_{\mathrm{ds}} i_{\mathrm{Q} \_ \text {on }}}{2}\left[\frac{C_{\text {iss }}\left(V_{\text {miller }}-V_{\mathrm{th}}\right)}{V_{\text {gate }}-0.5\left(V_{\text {miller }}+V_{\mathrm{th}}\right)}+\frac{C_{\mathrm{rss}} V_{\mathrm{ds}}}{V_{\text {gate }}-V_{\text {miller }}}\right]$

$P_{\mathrm{Q} \_ \text {off }}=\frac{f_{\mathrm{s}} R_{\mathrm{g}} V_{\mathrm{ds}} i_{\mathrm{Q} \_ \text {off }}}{2}\left[\frac{2 C_{\text {iss }}\left(V_{\text {miller }}-V_{\mathrm{th}}\right)}{V_{\text {miller }}+V_{\mathrm{th}}}+C_{\mathrm{rss}} \frac{V_{\mathrm{ds}}}{V_{\text {miller }}}\right]$

where $f_{\mathrm{s}}$ is the switching frequency; $R_{\mathrm{g}}$ is the driving resistor; $V_{\mathrm{ds}}$ is the voltage stress of the switch; $i_{\mathrm{Q}}$ on is the current through the switch when Q is turned on; $V_{\text {gate }}$ is the driving voltage; $C_{\mathrm{iss}}, C_{\mathrm{rss}}, V_{\text {miller }}, V_{\mathrm{th}}$ are the parasitic parameters of the switch, referring to the datasheet of the switch.

The conduction loss can be derived as:

$P_{\mathrm{Q} \_ \text {con }}=I_{\mathrm{Q} \_ \text {rms }}^{2} R_{\mathrm{dson}}$

where $I_{\mathrm{Q} \text { rms }}$ is RMS current through the switch; $R_{\mathrm{dson}}$ is the on-state resistor of the switch.

2) Power loss of the diodes $D_{1}, D_{o 1}, D_{02}, D_{03}$

The voltage drop of the diode can be viewed as a constant value. Then the power loss of $D_{1}, D_{01}, D_{02}, D_{03}$ can be derived as:
$\left\{\begin{array}{l}P_{\mathrm{D} 1}=V_{\mathrm{f} \_ \text {D1 }} I_{\mathrm{D} 1 \_ \text {avg }} \\ P_{\mathrm{Do1}}=V_{\mathrm{f} \_ \text {Do1 } 1} I_{\text {Do1 } \_ \text {avg }} \\ P_{\mathrm{Do} 2}=V_{\mathrm{f} \_D 02} I_{\mathrm{Do} 2 \_a v g} \\ P_{\mathrm{Do} 3}=V_{\mathrm{f} \_ \text {Do3 }} I_{\text {Do3_avg }}\end{array}\right.$

where $V_{\mathrm{f} \_\mathrm{D} 1}, V_{\mathrm{f} \_ \text {Do1 }}, V_{\mathrm{f} \_\mathrm{Do} 2}, V_{\mathrm{f} \_ \text {Do3 }}$ are the voltage drops of $\mathrm{D}_{1}, \mathrm{D}_{\mathrm{o} 1}, \mathrm{D}_{\mathrm{o} 2}, \mathrm{D}_{\mathrm{o} 3}$, which are listed in the datasheet; $I_{\mathrm{D} 1 \_ \text {avg }}$, $I_{\text {Do1_avg }}, I_{\text {Do2_avg }}, I_{\text {Do3_avg }}$ are the average currents through $\mathrm{D}_{1}, \mathrm{D}_{\mathrm{o} 1}, \mathrm{D}_{\mathrm{o} 2}, \mathrm{D}_{\mathrm{o} 3}$, respectively.

3) Power loss of the inductor $L_{1}$, and coupled inductor $L_{\mathrm{cp}}$

The power losses of $L_{1}$ and $L_{\mathrm{cp}}$ include the copper loss and the core loss. The copper loss of $L_{1}, L_{\mathrm{cp}}$ can be derived as:

$$
\left\{\begin{aligned}
P_{\mathrm{L} 1 \_\mathrm{cu}}= & I_{\mathrm{L} 1 \_\mathrm{dc}}^{2} R_{\mathrm{L} 1 \_\mathrm{dc}}+I_{\mathrm{L} 1 \_\mathrm{ac}}^{2} R_{\mathrm{L} 1 \_\mathrm{ac}} \\
P_{\mathrm{Lcp} \_\mathrm{cu}}= & I_{\mathrm{Lcp} \_\mathrm{p} \_\mathrm{dc}}^{2} R_{\mathrm{Lcp} \_\mathrm{p} \_\mathrm{dc}}+I_{\mathrm{Lcp} \_\mathrm{s} \_\mathrm{dc}}^{2} R_{\mathrm{Lcp} \_\mathrm{s} \_\mathrm{dc}} \\
& +I_{\mathrm{Lcp} \_\mathrm{p} \_\mathrm{ac}}^{2} R_{\mathrm{Lcp} \_\mathrm{p} \_\mathrm{ac}}+I_{\mathrm{Lcp} \_ \text {s_ac }}^{2} R_{\mathrm{Lcp} \_ \text {s_ac }}
\end{aligned}\right.
$$

where $I_{\mathrm{L} 1 \_\mathrm{dc}}$ and $I_{\mathrm{L} 1 \_a c}$ are the dc current and ac RMS current of $L_{1}$, respectively; $I_{\text {Lcp_p_dc }}$ and $I_{\text {Lcp_p_ac }}$ are the dc current and ac RMS current of the primary winding, respectively; $I_{\text {Lcp_s_dc }}$ and $I_{\text {Lcp_s_ac }}$ are the dc current and ac RMS current of the secondary winding, respectively; $R_{\mathrm{L} 1 \_\mathrm{dc}}, R_{\mathrm{L} 1 \_\mathrm{ac}}, R_{\mathrm{Lcp} \_ \text {_dc }}, R_{\mathrm{Lcp} \_\mathrm{s} \_\mathrm{dc}}, R_{\mathrm{Lcp} \_\mathrm{p} \_\mathrm{ac}}$ and $R_{\mathrm{Lcp} \_\mathrm{s} \_\mathrm{ac}}$ can be measured by the impedance analyzer.

The core loss of $L_{1}, L_{\mathrm{cp}}$ can be derived as:

$$
\begin{aligned}
& \left\{\begin{array}{l}
P_{\mathrm{L} 1 \_f e}=k f_{\mathrm{s}}^{m} \Delta B_{\mathrm{L} 1}^{n} V_{\mathrm{e}} \\
P_{\mathrm{Lcp} \_\mathrm{fe}}=k f_{\mathrm{s}}^{m} \Delta B_{\mathrm{Lcp}}^{n} V_{\mathrm{e}}
\end{array}\right. \\
& \left\{\begin{array}{l}
\Delta B_{\mathrm{L} 1}=\frac{\left(V_{\mathrm{g}}+V_{\mathrm{Ca} 2}\right) D T_{\mathrm{s}}}{N_{\mathrm{L} 1} A_{\mathrm{e}}} \\
\Delta B_{\mathrm{Lcp}}=\frac{V_{\mathrm{Ca} 1} D T_{\mathrm{s}}}{N_{\mathrm{Lcp} \_\mathrm{p}} A_{\mathrm{e}}}
\end{array}\right.
\end{aligned}
$$

where $V_{\mathrm{e}}$ is the core volume; $A_{\mathrm{e}}$ is the effective area of the core; $k, m, n$ can refer to the datasheet of the core; $N_{\mathrm{L} 1}$ is the turns of $L_{1} ; N_{\text {Lcp p p }}$ is the turns of the primary winding.

\section{References}

[1] Tseng K, Huang C, Shih W (2013) A high step-up converter with a voltage multiplier module for a photovoltaic system. IEEE Trans Power Electron 28(6):3047-3057

[2] Leyva-Ramos J, Lopez-Cruz J, Ortiz-Lopez M et al (2013) Switching regulator using a high step-up voltage converter for fuel-cell modules. IET Power Electron 6(8):1626-1633

[3] Velasco-Quesada G, Guinjoan-Gispert F, Piqué-López R et al (2009) Electrical PV array reconfiguration strategy for energy extraction improvement in grid-connected PV systems. IEEE Trans Ind Electron 56(11):4319-4331 
[4] Tseng K, Huang C (2014) High step-up high-efficiency interleaved converter with voltage multiplier module for renewable energy system. IEEE Trans Ind Electron 61(3):1311-1319

[5] Young C, Chen M, Chang T et al (2013) Cascade CockcroftWalton voltage multiplier applied to transformerless high stepup DC-DC converter. IEEE Trans Ind Electron 60(2):523-537

[6] Chen S, Liang T, Yang L et al (2013) A boost converter with capacitor multiplier and coupled inductor for ac module applications. IEEE Trans Ind Electron 60(4):1503-1511

[7] Ellis M, von Spakovsky M, Nelson D (2001) Fuel cell systems: efficient, flexible energy conversion for the 21 st century. Proc IEEE 89(12):1808-1818

[8] Li W, He X (2011) Review of nonisolated high-step-up DC/DC converters in photovoltaic grid-connected applications. IEEE Trans Ind Electron 58(4):1239-1250

[9] Tofoli F, Pereira D, Paula W et al (2015) Survey on non-isolated high-voltage step-up DC-DC topologies based on the boost converter. IET Power Electron 8(10):2044-2057

[10] Huber L, Jovanovic MM (2000) Design approach for server power supplies for networking applications. In: Proceedings of IEEE applied power electronics conference and exposition, New Orleans, USA, 6-10 February 2000. pp 1163-1169

[11] Mostaan A, Zeinali H, Asghari S et al (2014) Novel high step up DC/DC converters with reduced switch voltage stress. In: Proceedings of Power electronics, drive systems and technologies conference, Tehran, Iran, 5-6 February 2014. pp 379-384

[12] Evran F, Aydemir M (2014) Isolated high step-up DC-DC converter with low voltage stress. IEEE Trans Power Electron 29(7):3591-3603

[13] Zhu M, Yu K, Luo F (2010) Switched inductor Z-source inverter. IEEE Trans Power Electron 25(8):2150-2158

[14] Nguyen M, Lim Y, Cho G (2011) Switched-inductor quasi-Zsource inverter. IEEE Trans Power Electron 26(11):3183-3191

[15] Li D, Loh P, Zhu M et al (2013) Enhanced-boost Z-source inverters with alternate-cascaded switched- and tapped-inductor cells. IEEE Trans Ind Electron 60(9):3567-3578

[16] Li D, Loh P, Zhu M et al (2013) Generalized multicell switchedinductor and switched-capacitor Z-source inverters. IEEE Trans Power Electron 28(2):837-848

[17] Siwakoti Y, Peng F, Blaabjerg F et al (2015) Impedance-source networks for electric power conversion part I: a topological review. IEEE Trans Power Electron 30(2):699-716

[18] Vinnikov D, Roasto I (2011) Quasi-Z-source-based isolated DC-DC converters for distributed power generation. IEEE Trans Ind Electron 58(1):192-201

[19] Siwakoti Y, Blaabjerg F, Loh P et al (2014) High-voltage boost quasi-Z-source isolated DC-DC converter. IET Power Electronics 7(9):2387-2395

[20] Husev O, Liivik L, Blaabjerg F et al (2015) Galvanically isolated quasi-Z-source DC-DC converter with a novel ZVS and ZCS technique. IEEE Trans Ind Electron 62(12):7547-7556

[21] Yang L, Qiu D, Zhang B et al (2014) A modified Z-source DCDC cnverter. In: Proceedings of European conference on power electronics and applications, Lappeenranta, Finland, 26-28 August 2014. pp 1-9

[22] Zhao Q, Lee F (2003) High-efficiency, high step-up DC-DC converters. IEEE Trans Power Electron 18(1):65-73

[23] Tseng K, Huang C, Cheng C (2016) A single-switch converter with high step-up gain and low diode voltage stress suitable for green power-source conversion. IEEE Journal of Emerging \& Selected Topics in Power Electronics 4(2):363-372

[24] Lin T, Chen J, Hsieh Y (2013) A novel high step-up DC-DC converter with coupled-inductor. In: Proceedings of International future energy electronics conference, Tainan, Taiwan, China, 3-6 November 2013, 92(1):777-782
[25] Wai R, Lin C, Chu C (2004) High step-up DC-DC converter for fuel cell generation system. In: Conference of IEEE industrial electronics society, Busan, Korea, 2-6 November 2004

[26] Wai R, Lin C (2005) High-efficiency, high-step-up DC-DC converter for fuel-cell generation system. Proc IEE Proc Electr Power Appl 152(5):1371-1378

[27] Wu T, Lai Y, Hung J et al (2008) Boost converter with coupled inductors and buck-boost type of active clamp. IEEE Trans Ind Electron 55(1):154-162

[28] Wu T, Lai Y, Hung J et al (2005) An improved boost converter with coupled inductors and buck-boost type of active clamp. In: Proceedings of Industry applications conference, Hong Kong, China, 2-6 October 2005

[29] Evran F, Aydemir M (2013) Z-source-based isolated high stepup converter. IET Power Electron 6(1):117-124

[30] Evran F, Aydemir M (2012) A coupled-inductor Z-source based DC-DC converter with high step-up ratio suitable for photovoltaic applications. In: Proceedings of IEEE international symposium on power electronics for distributed generation systems, Aalborg, Denmark, 25-28 June 2012. pp 647-652

[31] Seong H, Kim H, Park K et al (2010) Zero-voltage switching flyback-boost converter with voltage-doubler rectifier for high step-up applications. In: Proceedings of IEEE energy conversion congress and exposition, Atlanta, USA, 12-16 September 2010. pp 823-829

[32] Hsieh Y, Chen J, Liang T et al (2013) Novel high step-up DCDC converter for distributed generation system. IEEE Trans Ind Electron 60(4):1473-1482

[33] Ajami A, Ardi H, Farakhor A et al (2015) A novel high step-up $\mathrm{dc} / \mathrm{dc}$ converter based on integrating coupled inductor and switched-capacitor techniques for renewable energy applications. IEEE Trans Power Electron 30(8):4255-4263

[34] Sathyan S, Suryawanshi H, Ballal M et al (2015) Soft switching DC-DC converter for distributed energy sources with high step up voltage capability. IEEE Trans Ind Electron 62(11):7039-7050

[35] Liu V, Zhang L (2014) Design of high efficiency Boost-Forward-Flyback converters with high voltage gain. In: Proceedings of IEEE international conference on control and automation, Taichung, Taiwan, China, 18-20 June 2014. pp 1061-1066

Gang WU (S'16) received the B.S. degrees in electrical engineering and automation from Nanjing University of Aeronautics and Astronautics (NUAA), Nanjing, China, in 2011, where he is currently working toward the Ph.D. degree in electrical engineering. His current research interests include high step-up DC-DC converter and renewable energy generation systems.

Xinbo RUAN (M'97-SM'02-F'16) received the B.S. and Ph.D. degrees in electrical engineering from Nanjing University of Aeronautics and Astronautics (NUAA), Nanjing, China, in 1991 and 1996, respectively. In 1996, he joined the College of Automation Engineering, NUAA, where he became a Professor in 2002. Since 2008 to 2011, he was also with the College of Electrical and Electronic Engineering, Huazhong University of Science and Technology, China. He is the author or co-author of seven books and more than 200 technical papers published in journals and conferences. His main research interests include soft-switching power electronics converters, power electronics system integration and renewable energy generation system. From 2005 to 2013, he served as Vice President of the China Power Supply Society. Currently, he serves as an Associate Editor for the IEEE Transactions on Industrial Electronics, the IEEE Journal of Emerging and Selected Topics on Power Electronics, the IEEE Transactions on Power Electronics and the IEEE Transactions on Circuits and Systems-II. 
Zhihong YE (M'00) received B.S. and M.S. degrees in electrical engineering from Tsinghua University, Beijing, China, in 1992 and 1994, respectively. He received Ph.D. degree from the Bradley department of electrical and computing engineering, Virginia Polytechnic Institute and State University, in 2000. From 2000 to 2005, he worked for General Electric Global Research Center as an electrical engineer in Niskayuna, New York. From 2005 to 2006, he worked for Dell as a commodity quality manager. Since 2006, he has been working for LiteOn Technology Corp., as the Director of Research and Development. His research interests include high density, high efficiency power supply for computing, communication and consumer electronics applications, digital control, power converter topologies and controls, soft-switching techniques, etc. $\mathrm{He}$ holds 17 US patents, and has published more than 30 technical papers in Transactions and international conferences. 